\title{
Fifty shades of morphosyntactic microvariation
}

\section{Cruschina, Silvio}

de Gruyter

2021

Cruschina , S \& Calabrese , A 2021, Fifty shades of morphosyntactic microvariation . in M-O Hinzelin , N Pomino \& E-M Remberger (eds) , Formal Approaches to Romance

Morphosyntax . Linguistische Arbeiten , no. 576 , de Gruyter , Berlin , pp. 145-198 . https://doi.org/10.1515/9783110

http://hdl.handle.net/10138/324319

https://doi.org/10.1515/9783110719154-006

acceptedVersion

Downloaded from Helda, University of Helsinki institutional repository.

This is an electronic reprint of the original article.

This reprint may differ from the original in pagination and typographic detail.

Please cite the original version. 
Silvio Cruschina \& Andrea Calabrese

\title{
Fifty shades of morphosyntactic microvariation
}

\author{
Motion verb constructions in southern Italian dialects
}

\begin{abstract}
In this paper, we analyse Motion Verb Constructions (MVCs) in southern Italian dialects, especially in Sicily and Apulia, which provide an ideal illustration of morphosyntactic microvariation. Depending on the grammatical status of the motion verb, we can distinguish between MVCs in which a lexical verb selects a purpose clause and those that involve a restructuring configuration where the motion verb behaves as a functional verb. We focus on the latter configuration and show that in these MVCs, the second verb can occur either as an infinitive or as a verb inflected for the same features as the motion verb. Following the most recent developments in Distributed Morphology, we then offer an analysis of the morphosyntactic and word-internal structure that surfaces as periphrastic morphology, and propose that the difference between the infinitival restructuring and double inflection is due to the nature of the agreement node within the verbal complex. Within this account, double inflection is simply viewed as a case of agreement within the extended VP which arises independently from restructuring. Finally, the defective paradigm of some MVCs and the configurations in which the motion verb has become a prefixal element are discussed and analysed as the result of specific wordinternal morphological operations.
\end{abstract}

Keywords: motion verbs, southern Italian dialects, Sicilian, restructuring, agreement, double inflection, impoverishment, affixation.

\section{Introduction: Motion verb constructions and morphosyntactic variation}

Crosslinguistically, motion verbs such as go or come are commonly found in complex constructions that display a variety of morphosyntactic patterns. For the purpose of this

Silvio Cruschina: Department of Languages, University of Helsinki, silvio.cruschina@helsinki.fi

Andrea Calabrese: Department of Linguistics, University of Connecticut,

andrea.calabrese@uconn.edu 
paper, and in reference to southern Italian dialects, we define Motion Verb Constructions (MVCs) as those constructions that are composed of a motion verb (go, come, pass (by), etc.) and a main lexical verb. We will refer to the former as V1 and to the latter as V2, as illustrated in (1). V1 and V2 are often linked by a preposition or pseudo-coordination (P); however, this not obligatory and is in fact absent in some dialects:

\section{(1) $\mathrm{V} 1+(\mathrm{P})+\mathrm{V} 2$}

The V1 in MVCs can in principle be a lexical verb, but in this paper, we will concentrate on those cases in which V1 has grammaticalized into an aspectual marker. The development of a future tense from a construction with the verb GO, where the latter has been 'bleached' of its original movement meaning, is a cross-linguistically common grammaticalization path (see Bybee et al. 1994). Crucially, there is no southern Italian dialect in which Go has developed the temporal function that it has in many other Romance varieties, such as Spanish, Portuguese, and French, where in MVCs V1 functions as a future auxiliary (see, e.g., Squartini 1998, among many others).

An examination of the syntactic and morphological properties of V1 in southern Italian MVCs reveals different types of morphosyntactic structures (Cardinaletti \& Giusti 2001, 2003, Manzini \& Savoia 2005, Cruschina 2013, Di Caro 2015, 2018, 2019, Ledgeway 2016, Andriani 2017). When it heads a main clause followed by an infinitival clause of purpose, V1 clearly behaves as a lexical verb. This is exemplified in (2):

$$
\begin{aligned}
& \text { Ci jivu pi ci purtari na littira. } \\
& \text { there go.PST.1sG to him.DAT bring a letter } \\
& \text { 'I went there to bring him a letter.' }
\end{aligned}
$$

This sentence is uncontroversially an instance of a biclausal MVC where the preposition 'pi' functions as a subordinating conjunction that introduces the purpose clause. In this paper, however, we concentrate on monoclausal MVCs, which we investigate using tools and insights from formal approaches to syntactic and morphological variation.

Further 'shades' of morphosyntactic microvariation may be identified with respect to other elements of the MVC, including the absence of P between V1 and V2, the presence of connecting elements other than P (e.g. $c u$ in Salentino, $m i$ in Messinese), and clitic placement in restructuring contexts (e.g. before V2 in some Salentino dialects). For reasons of space, however, we will not discuss these aspects here and leave them for future research. For an comparative overview, see Di Caro (2019). 


\section{Restructuring: An integrated approach}

In most Western Romance varieties, when verbs such as GO and COME feature in MVCS they are typically followed by an infinitive. We will refer to this construction as the Infinitival MVC. Here is an example from the Apulian dialect spoken in Bari:

(3) Mə vògg' a 'ccattà $u$ cappìddə névə.

(Bari, Apulia)

me go.PRS.1sG to buy.INF the hat new

'I go buy a new hat.'

(Andriani 2017: 231)

The Infinitival MVC in southern Italy is not the only option for speakers: a number of different combinations of a motion $\mathrm{V} 1$ followed by a finite $\mathrm{V} 2$ are available. The two verbs in the constructions can be connected by different connecting elements, most commonly by the linker ' $a$ '. ${ }^{1}$ Following Cruschina (2013), we use the name Doubly Inflected Construction (DIC) for this kind of MVC, where the two verbs act as a single predicate and share the very same inflectional features. Example of DIC are provided below, where both V1 and V2 are in the 1st person singular (4), in the 3rd person singular (5), and in the 3 rd person plural (6) of the present indicative: ${ }^{2}$

Vaju a pigghiu u pani.
go.PRS.1sG to take.PRS.1sG the bread
'I go to fetch the bread.'
(Cardinaletti \& Giusti 2001: 373)

(Marsala, Sicily)

(Cardinaletti \& Giusti 2001: 373)

\footnotetext{
지구

${ }^{1}$ For the sake of simplicity, we have glossed the connecting element $a$ as if it corresponded to the homophonous preposition $a$ 'to' in the same varieties. Since Ascoli $(1886,1901)$, however, a long tradition of scholars have considered this element as the continuation of the Latin coordinating conjunction AC used in spoken and late Latin (see also Rohlfs 1969: §710, §761, Leone 1973, Sornicola 1976, Cardinaletti \& Giusti 2001, Ledgeway 2016, Di Caro 2019). Indeed, in some cognate Calabrian dialects the connective element is the same as the coordinating conjunction $e$ from Latin ET (see Rohlfs 1969: §759). For this reason, the construction is treated as an instance of pseudo-coordination in several studies (see, e.g., Ledgeway 2016, Di Caro 2018, 2019). In any case, as argued in Cruschina (2013: 271), the origin of the connecting element is not relevant to the synchronic analysis of DIC, given that it is now desemanticized and contributes no meaning to the construction.

${ }^{2}$ The motion verbs that most typically appear in DIC are the local equivalents of go, come, come by/pass and send. Other verbs may enter the construction as V1 is some dialects. See Di Caro $(2018,2019)$ for a review of the additional motion verbs that can occur in DIC in different Sicilian varieties. On the special properties of send as V1, which involves both a motion and a causative semantics, see Todaro \& Del Prete (2018) and Del Prete \& Todaro (2020).
} 
$(5)$
U veni
a piglia
dopu.
him come.PRS.3SG to collect.PR.3SG later

(Mussomeli, Sicily)

'He is coming to pick him up later.'

(Cruschina 2013: 266)

(6)
'vonə (a) m'mandzənə.
go.PRS.3PL to eat.PRS.3PL
'They're going to eat.'
(Ledgeway 2016: 159)

(Martina Franca, Apulia)

In their analysis, Cardinaletti \& Giusti (2001) compare DIC with the Infinitival MVC and, on the basis of a number of syntactic and semantic tests, convincingly show that DIC (the inflected construction, in their terminology) is monoclausal. At the same time, they argue that the motion verbs involved as V1 in DIC are "lexical categories merged as functional heads" in the extended projection of the V2. More specifically, they define these verbs as "semi-lexical verbs" because, while it is true that they lack or have lost their canonical lexical properties, they still retain their motion semantics. ${ }^{3}$

It is important to observe, however, that even in Infinitival MVCs in Sicilian dialects, two different structures may be involved: a) a lexical verb governing a purpose clause; and b) a restructuring configuration of the functional type, in which V1 behaves as a functional head (see Rizzi 1976, 1978, Cinque 2001, 2006; on the distinction between lexical and functional restructuring, see Wurmbrand 2001, 2004). Assuming that restructuring involves clitic climbing, the contrasts in (7) and(8) show the existence of these two MVC constructions. They are distinguished by V1's (in)ability in a restructuring configuration to select either for the arguments or for the adjuncts that are typical of motion verbs. While V1 can select for the directional argument agghiri a casa ('towards home'), which separates V1 from V2 in the sentence in (7a), the same argument cannot be selected by V1, in (7b), which is characterized by clitic climbing, independently of its position within the sentence. The same difference can be observed in the presence of an adjunct to the lexical motion V1 in (8a), such as the instrumental cu a machina ('by car'), which cannot be combined with the functional V1 of ( $8 \mathrm{~b})$ because it has lost its lexical and selectional properties. In fact, a verb merged as a functional head cannot project its arguments and cannot combine with adjuncts that typically modify lexical (motion) VPs. We can conclude that the infinitival complement in (7a)and (8a) is truly a purpose clause, whereas that in (7b) and ( $8 b)$ is part of a restructuring construction where V1 is a functional head.

\footnotetext{
저?

${ }^{3}$ See Cardinaletti \& Giusti (2019) for a refinement of this analysis, according to which V1 is merged in $t$, a head immediately above T. See Del Prete \& Todaro (2019) for a different semantic analysis of the single event interpretation.
} 
(7)
a. Va agghiri a casa a mangiari.
go.3sG towards to home to eat.INF
'He goes towards home to eat.'
(Cardinaletti \& Giusti 2001: 377)
b. La va (*agghiri a casa) a mangiari (*agghiri a casa).
it= go.3sg towards to home to eat.3sg towards to home

(Marsala, Sicily)

(8)
a. Peppe va a mangiari c'a machina. (Marsala, Sicily) Peppe go.3sg to eat.INF with-the car
'Peppe goes to eat by car.'
(Cardinaletti \& Giusti 2001: 379)
b. Peppe la va a mangiari (*c'a machina).
Peppe it=go.3sg to eat.3sG with-the car

The same properties displayed by the restructured Infinitival MVC in (7) and (8) are characteristic of the DIC, as shown in (9) and (10):

$\begin{array}{lll}\text { (9) Va } & \text { (*agghiri a casa) a mangia (*agghiri a casa). (Marsala, Sicily) } \\ \text { go.3sG towards to home to eat.3sg towardsto home } & \end{array}$

(Cardinaletti \& Giusti 2001: 377)

(10) *Peppe va a mangia c'a machina.
Peppe go.3sg to eat.3sg with-the car
(Cardinaletti \& Giusti 2001: 379)

The conclusion is that DICs are in fact restructuring configurations in which V1 behaves as a functional head. This can account for the different properties of DIC with respect to the Infinitival MVC first examined in Cardinaletti \& Giusti (2001), including obligatory clitic climbing, single event interpretation, indivisibility, and incompatibility with the arguments and adjuncts typically associated with motion verbs (see Cardinaletti \& Giusti 2001, 2003, Manzini \& Savoia 2005, Cruschina 2013, and Di Caro 2019 for more details).

An underlying problem with the structural distinction between Infinitival MVC and DIC is their interpretation. From a semantic viewpoint, the distinction between the two structures is not particularly clear, leading Cardinaletti \& Giusti (2001) to claim that V1 retains the semantics of a motion verb and should therefore not be assimilated to an auxiliary proper. Here, we would like to suggest that in DIC and in the Infinitival MVC with restructuring, but not in the structure where the infinitival V2 is part of a purpose clause, the motion verb V1 is a functional verb heading Cinque's (1999) andative aspect projection. This aspect signals that a distance away from the speaker must be covered for the action to be realized or executed, thus matching the directional properties of the 
verb GO. In the case of COME as V1, a venitive aspect is encoded, signalling that the distance to be covered is towards the speaker. ${ }^{4}$

In other words, the V1 in DIC and in the Infinitival MVC with restructuring is semantically bleached so as to provide specific aspectual information about the event structure, under a single event interpretation. ${ }^{5}$ Under this analysis, the motion meaning is retained to a certain extent, in line with native speakers' intuitions, but as a functional aspect rather than as a lexical semantic property.

DIC differs from the usual Italo-Romance functional restructuring cases, however, in that it presents double inflection as its hallmark. In this respect, we propose that double inflection arises independently of restructuring, and that it can be analysed as a case of agreement within the extended $\mathrm{VP}$ which takes place via concord, through a mechanism resembling adjectival agreement (Baker 2010). We will return to this point in Sections 3 and $4 .^{6}$

In some contexts, DIC has completely lost its motion meaning and instead expresses an element of surprise about a past event (Sornicola 1976, Cruschina 2013): ${ }^{7}$

Cuannu u vitti ca sunava nna banna,
when him see.PST.1SG that play.IMRF.PST.3SG in-the band
vaju a pruvu na gioia!
go.PRS.1SG to feel.PRS.1SG a joy
'When I saw him play in the band, I felt such a joy!'

Ogellannu va a capita ca ci vinni
last-year go.3sG to happen.3sg that to-him come.PST.3SG
a frevi tri boti!
the fever three times
'Last year it happened that he had a fever three times!'

(13) Nun va a mmori propriu oi? not go.3sg to die.3sg right today 'He just had to go and die today...'

\footnotetext{
ब四?

${ }^{4}$ We assume that the venitive aspect is encoded in an independent functional head. In this paper, however, we will focus on MVCs involving the andative functional head and will not further discuss the venitive aspect.

${ }^{5}$ Cardinaletti \& Giusti (2001: § 3.7.2) convincingly show that DIC, unlike Infinitival MVC, expresses a single event.

${ }^{6}$ See Cardinaletti \& Giusti (2019) for an alternative analysis, according to which the features of V1 are parasitically copied on to the features of $\mathrm{V} 2$.

7 The examples in (11) and (12) are from the dialects of Mussomeli (Cruschina 2013: 279), while the example in (13) is from Delia (Di Caro 2019: 132).
} 
Generally, stative and unaccusative predicates are not compatible with MVCs as V2s. The examples above, however, show that with a desemanticized V1, stative and unaccusative V2 may occur in DIC. ${ }^{8}$

DICs show a great deal of morphosyntactic microvariation. A type of radical impoverishment is found in western and central Sicily, leading to an uninflected V1 in the whole paradigm (Cardinaletti \& Giusti 2001, 2003, 2019, Cruschina 2013):

$\begin{array}{llll}\text { (14) } & \text { 1SG } & \text { vaju a pigghiu } & \text { / va a pigghiu } \\ \text { 2SG } & \text { vai a pigghi } & \text { / va a pigghi } \\ \text { 3SG } & \text { va a pigghia } & \text { / va a pigghia } \\ \text { 3PL } & \text { vannu a pigghianu / va a pigghianu } \\ \text { IMPER.2SG } & \text { va pigghia } & \text { / va pigghia }\end{array}$

It is important to note that the impoverished forms in these Sicilian dialects are not limited to the verb GO, but are also found with other motion verbs (Cardinaletti \& Giusti 2019), and that the DIC version with invariant va as V1 (cf. (14)) coexists with the version in which GO displays regular endings.

In some areas of eastern Sicily (e.g. Marina di Ragusa, Acireale) the grammaticalization of V1 appears to have reached the final stage of affix (cf. (15)). Native speakers of these dialects are not always aware of this affix, which is realized at the beginning of the finite V2, and of its origins from the verb GO. The data in (15) and (16), from Di Caro (2015: 62-68), illustrate this advanced stage of grammaticalization (see also Di Caro 2019):
a. Voppigghju u pani. go+fetch.1sG the bread
1SG
b. Voppigghi u pani.
2SG
c. Vopigghja u pani.
3SG
d. Voppigghjamu u pani.
1PL
e. Voppigghjati u pani.
2PL
c. Voppigghjanu u pani.
3PL

(Marina di Ragusa, Sicily)

(16)
a. Occattu u giunnali. go+buy.1SG the newspaper 1SG
b. Occatti u giunnali.
2SG
c. Occattunu u giunnali. 3PL ... [full paradigm] ...

(Acireale, Sicily)

\section{즈?}

${ }^{8}$ We refer to Cruschina (in press) for an account of the development of the surprise meaning out of a motion verb. See also Cruschina (2018) for another monoclausal MVC characterized by the possibility of expressing surprise and unexpectedness. 
In this paper, we propose an account for the morphosyntactic differences between the Infinitival MVC with restructuring and DIC. Assuming the existence of an andative functional node, we will then address the variation in its morphosyntactic realization. It can be treated analytically as an independent verbal form (V1), but also synthetically as a prefixal element as in the cases in (15) and (16). What is the nature of these analytic and synthetic morphological treatments of this functional head? It should be noted that Cinque's (1999) cartographic approach to the functional skeleton of the verb, which we adopt here, is ill-equipped to deal with word-internal and word-external correlations such as those under investigation here: Cinque's approach relies on a lexicalist-word based view of syntax which can only adequately deal with word-external (analytic) distributional patterns but not with word-internal ones. It relates only to how sentences and phrases are constructed and not to how words are constructed. We will try to correct this problem by integrating Cinque's model into Distributed Morphology, a syntactic model of word construction.

We assume Cinque's complex functional structure (see (20) below) including the functional andative functional node. A fundamental issue that we will address is that of how this functional skeleton is mapped into surface PF forms. The key operation in mapping is head movement (head raising in our case) which moves the functional heads upwards cyclically and generates $X^{0}$ complexes (i.e. morphological words). As a result, verbal forms' construction follows, accordingly, the hierarchial functional structure (cf. the mirror principle). Three additional operations are needed to derive the verbal surface structure of Romance verbal forms. Two of them insert ornamental morphological pieces such as AGR (Halle \& Marantz 1993, Bobaljik 2000) and Thematic Vowels (OltraMassuet \& Arregi 2005). The third prunes nodes with non-overt exponents. This latter operation accounts for why Romance forms do not always have an agglutinative structure, that is, a cumulation of morphological nodes but also a fusional one in which more functional heads are represented by a single exponent. Instead of assuming Halle \& Marantz's (1993) fusion to account for the merging of these nodes, Calabrese (2019) proposes cyclic pruning of nodes with non-overt exponence followed by upward docking of the features that consequently become floating. This pruning operation radically simplifies the phonological realization of morphosyntactic structures, and accounts for the convergence of possibly complex morphosyntactic structures and their possibly simpler PF surface shape. It also eliminates fusion and its problematic look ahead relation with vocabulary items, and also removes the problem of exponential zero in surface representations.

We will also assume that periphrastic forms arise from the blocking of head movement along the lines of Bjorkman (2011), Calabrese (2019), Fenger (2020), Embick (2000) and Pietraszko (2018). A simple way of implementing this, without taking a stand with respect with above mentioned thories, is to propose that head movement from one head position in the extended functional verb projection to the one directly higher up may be subject to parametrization along a parameter that either allowes or does not 
allow movement from this position. As a consequence, also periphrastic structures, and the subsequent formation of auxiliaries, follow the hierarchial functional structure. We show that. in this way, we can capture the syntactic and morphological properties and processes that determine the different shades of microvariation in southern Italian MVCs.

\section{A morphosyntactic analysis of lexical and functional restructuring}

The theory of Distributed Morphology proposes a piece-based view of word formation, in which the syntax/morphology interface is made as transparent as possible by incorporating hierarchical structure into morphology; essentially, it assumes the input to morphology to be syntactic structure where morphosyntactic and semantic features (or feature bundles) are distributed over nodes forming morphemes (see Halle \& Marantz 1993). Morphology manipulates these syntactic structures and eventually converts them into linear sequences of phonological representations:

The Grammar

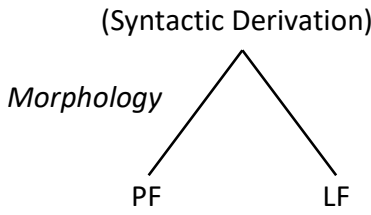

The derivation of all morphological forms then takes place in accordance with the architecture given in (17). Roots and other morphemes are combined into larger syntactic objects, which are moved when necessary (Merge, Move).

In Distributed Morphology, the phonological exponents of the different morphemes are listed in the Vocabulary as part of the vocabulary items, where each vocabulary item includes a phonological exponent and an associated set of features that governs its insertion into the terminal nodes of the morphosyntax. The (abstract) morphosyntactic representation is the input to phonological spell out where phonological realizations are assigned to the terminal nodes. In the simplest case, this component linearizes the hierarchical structure by adding phonological material to the abstract morphemes via a process called Vocabulary Insertion. During Vocabulary Insertion, individual Vocabulary Items (VI) - rules that pair a phonological exponent with a morphosyntactic contextare consulted, and the most specific $\mathrm{VI}$ that can apply to an abstract morpheme is inserted (in the so-called Elsewhere (Subset, Paninian) ordering).

Vocabulary Items are essentially instructions that insert phonological material into 
a terminal node given certain specific feature configurations in the terminal node and its adjacent environment. Abstract morphemes are thus said to be spelled out during Vocabulary Insertion. As shown by Bobaljik (2000) (see also Embick 2010), Vocabulary Insertion applies cyclically from the inside out, where cyclicity indicates step-by-step VI application to each terminal node:

(18) Vocabulary Insertion proceeds cyclically from the inside out.

We also assume Cinque's (1999) complex verbal functional structure in (19) and (20) (possibly reflecting the way our cognition analyses the world), in which restructuring verbs are auxiliary-like functional heads:

(19) [IP ... Modal field... Tense field... Aspectual field... [v ... Root])

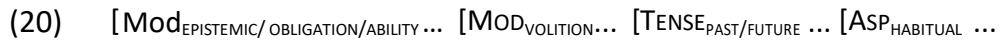

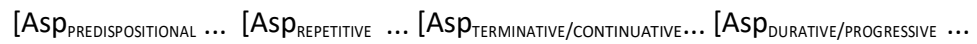

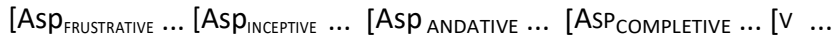

Cinque's original functional structure contains many different nodes dominating privative features. Following a more traditional approach in Generative Phonology, and subsequently in Distributed Morphology, we will use binary instead of privative features here. This will allow a simplification of Cinque's original functional skeleton, where different functional contrasts can be realized by combining feature specifications under the same node, as in (21). In addition we postulate that the nodes v, Voice and Asp are always syntactically active due to their syntactico-semantic roles in defining the basic inner and outer aspectual structure of the event and its argumental structure role; the other nodes may be optionally present. (For the sake of simplicity, only examples of the nodes present in Cinque's full model are mentioned here. The optional nodes are those in parentheses; they will be mentioned in later syntactic representations only when relevant in the analyses.) 
(21)

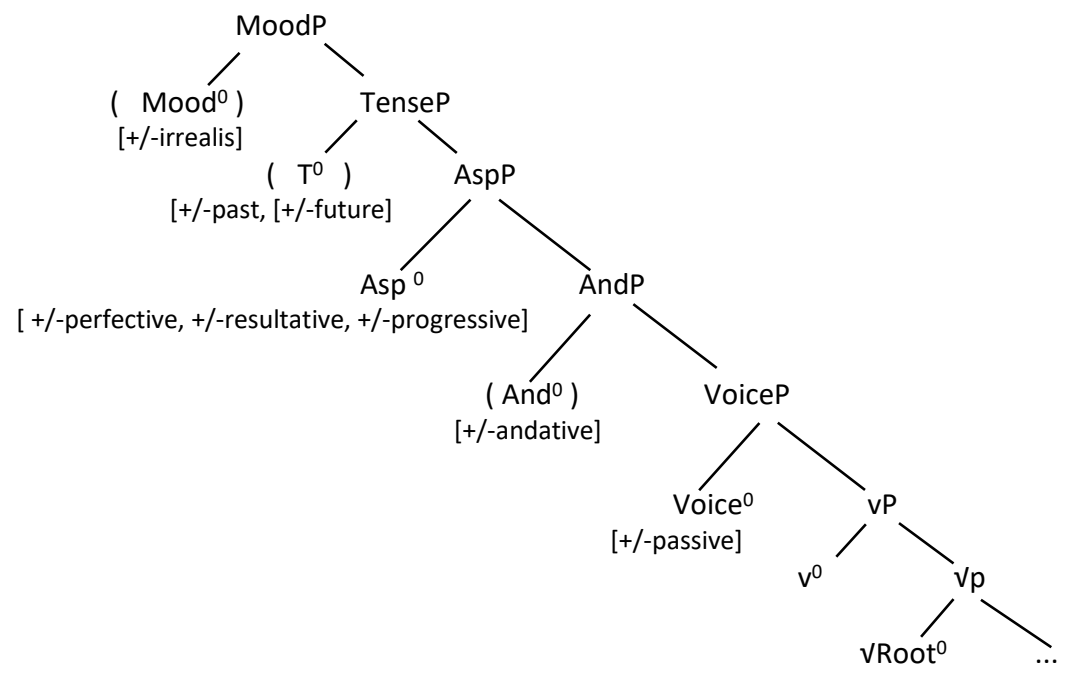

Assuming a universal hierarchical structure like that in (20) raises the question of how it is mapped onto surface morphological forms. If we look at the progressive as an example, we find that in analytic languages, it is, as expected, morphologically realized as an independent particle (see (22), from Cinque 2017: 558-559):

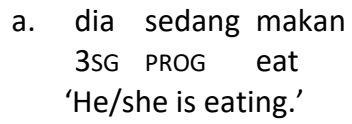

b. sow kəmbun di: roək nhiəm dog PROG look master]

(Stieng, Mon-Khmer) 'The dog is looking for its master.' (Bon 2014: 392)

In synthetic languages, it can be expressed periphrastically ('be at', 'be with', 'be in the middle/midst of ', 'do', 'be in the course of ', 'be on the way', 'now', 'hold', 'engaged/busy in', 'during', etc.), or through morphological affixation or other morphophonological means such as reduplication (examples from Cinque 2017: 559):

(23) Affixation
a. sawi ni-’afe-a-’a
banana eat-PROG-3SG.-IND
(Tauya, Madang) 
'He's eating bananas.'

(MacDonald 1985: 355)

b. n-iu ang me i-golang (Western Pantar, Alor-Pantar)

1SG.POSS-mother market LOC PROG-return

'My mother is returning from the market.'

(Holton 2014: § 7.2.2)

c. pəJu Ihamo tənge ki na-trop-w (rGyalrong, Sino-Tibetan, Qiangic) yesterday IHa.mo clothes IDEF PST-PROG-sew-3SG

'Yesterday IHa-mo was sewing a piece of clothing.'

(Prins 2011: 402)

(24) Reduplication
a. i. wadek 'to read'
ii. piload 'to pick breadfruit'
wadwadek 'to be reading'
(Mokilese)
(Harrison 1976: 220)
pilpiload 'to be picking breadfruit'

b. i. Daniel nùn gúfu-gūfú

Daniel PRES drive-drive

'Daniel is driving.'

ii. Daniel nùn gúf-à

Daniel PRES drive

'Daniel drives.'

(Chia 1976: 112ff)

Italo-Romance displays both a periphrastic and an affixal realization of the progressive. Thus, a few southern Italian varieties, e.g. the Salentino dialect spoken by one of the authors of this paper, display a synthetic form of the progressive. In this case the progressive is realized prefixally. Note the realization of subject AGR at the end of the verbal form. Below we contrast the Salentino synthetic progressive forms with those of Italian: ${ }^{9}$

(25)

Italian
sto perdendo
stay.1SG lose.GER
stai perdendo
stay.2sG lose.GER

\section{Salentino}

$\begin{array}{lll}\text { PRESENT } & & \\ & \text { sta } p^{\prime} p \varepsilon r d u & \text { 'I am losing' } \\ & \text { stay.1sg lose.1sg } & \\ & \text { sta } p^{\prime} p \varepsilon r d i & \text { 'you are losing' } \\ & \text { stay.2sg lose.2sG } & \end{array}$

\footnotetext{
बㄱ?

${ }^{9}$ There is no difference in meaning between the Italian and the Salentino progressive forms (pace Ledgeway 2016; see Calabrese 2019 for discussion).
} 


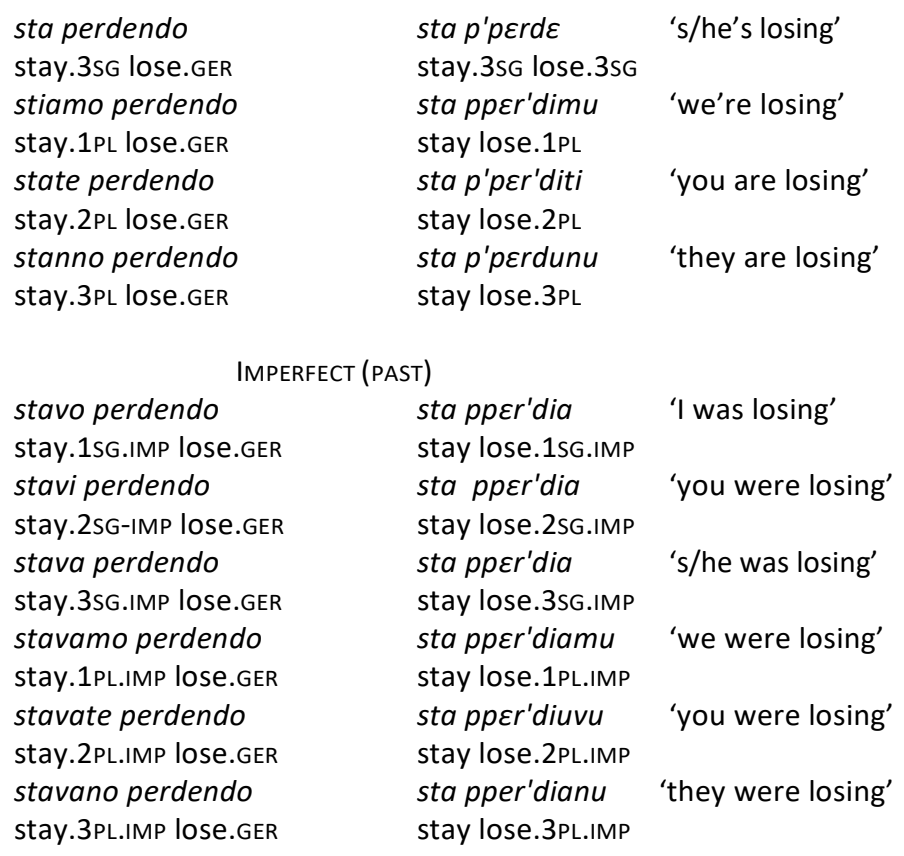

The /sta-/ in the right column is an integral part of the verbal word. This is shown by the fact that it cannot be separated from the other verbal constituent. For example, consider focal movement of V2, which is possible in southern Italian varieties in the case of staInfl $+\mathrm{V}$-ndo, but not in the form sta+V-Infl. At the same time, an adverb may occur between sta-Infl and V-ndo but not between sta and V-Infl:
a. Perdendo, lo stanno.
lose.GER it= stay
'They are losing it.'
b. Lo stanno sempre controllando.
it=stay always check.GeR
'They are always checking on it.'
a. *Perdunu, lu sta.
lose.3PL it=stay
b. * Lu sta sempre controllanu it= stay always check.3PL

As mentioned above, a fundamental issue for Cinque's lexicalist theory is how to account for the surface morphological realization of the functional structure in (21). Calabrese 
(2019) proposes a model that does account for this mapping of functional structure into surface verbal forms. This model also accounts for when periphrastic morphology occurs. Here we introduce this model by first illustrating the derivation of simple forms such as Italian mangiava 'eat.IMP.3SG' or mangia 'eat.PRES.3SG' and we will then go on with the issue of progressive aspect and consider the variation observed in this case between periphrasis and affixation.

\subsection{The functional structure of periphrastic morphology}

In Calabrese (2019), it is proposed that the affixal properties of functional heads follow from the the morphological requirement in (28): ${ }^{10}$

\section{Synthetic morphology principle:}

A functional head $\mathrm{Y}^{0}$ must be adjoined to a root or to $\mathrm{X}^{0}$ complex including a root.

In this system, syntactic representations in violation of (28) are repaired by $m$-word formation through the operation in (29), from Harizanov \& Gribanova (2019) (for the sake of simplicity, the alternative operation of head lowering is not covered in this paper since it is not directly relevant to the analysis developed here; see Calabrese 2019 for discussion): $:^{11}$

(29) A syntactic complementation relation $\left[\mathrm{X}^{0}\left[{ }_{\mathrm{YP}} \ldots \mathrm{Y}^{0}[\mathrm{zP} \ldots]\right.\right.$ ] may be realized in the morphology as a complex head by:

Head Raising:

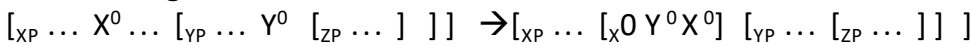

(where $\mathrm{Y}^{0}$ and $\mathrm{X}^{0}$ are heads, $\mathrm{X}^{0} \mathrm{c}$-commands $\mathrm{Y}^{0}$, and there is no head $\mathrm{Z}^{0}$ that $\mathrm{c}$ commands $Y^{0}$ and is c-commanded by $X^{0}$ )

\footnotetext{
저의

${ }^{10}$ If we assume that category-defining $X^{0}$ nodes are functional elements, we can also account for why they must be adjoined to roots.

${ }^{11}$ In this approach, a single mechanism - the synthetic morphology principle (28) - with head raising (and head lowering) as the associated repair implements word formation. Such an approach is simpler, and more parsimonious, than other approaches such as that of Bjorkman (2011) where m-word formation (head movement in her theory) is associated with infl-agreement, or Pietraszko (2017) where word formation can be implemented by the mechanism of c-selection with $\mathrm{m}$-word formation (head movement in her theory) as an additional strategy. It is closer to what has been proposed by Arregi \& Pietraszko (2018) with a single operation (Generalized Head raising) including both head raising and lowering.
} 
Given the syntactic structure in (30), head raising generates the structure in (31):

(30)<smiles>[Y][PH2+][P+]([1H])(C)C</smiles>

(31) A word-generated by head raising:

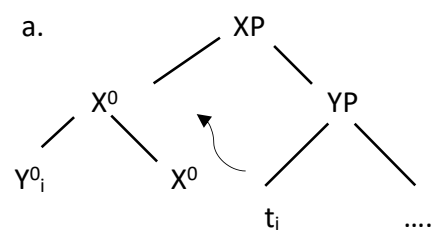

Therefore, given the structure in (21), head raising to satisfy (28) will create the structure in (32) by moving constituents upwards cyclically: ${ }^{12}$

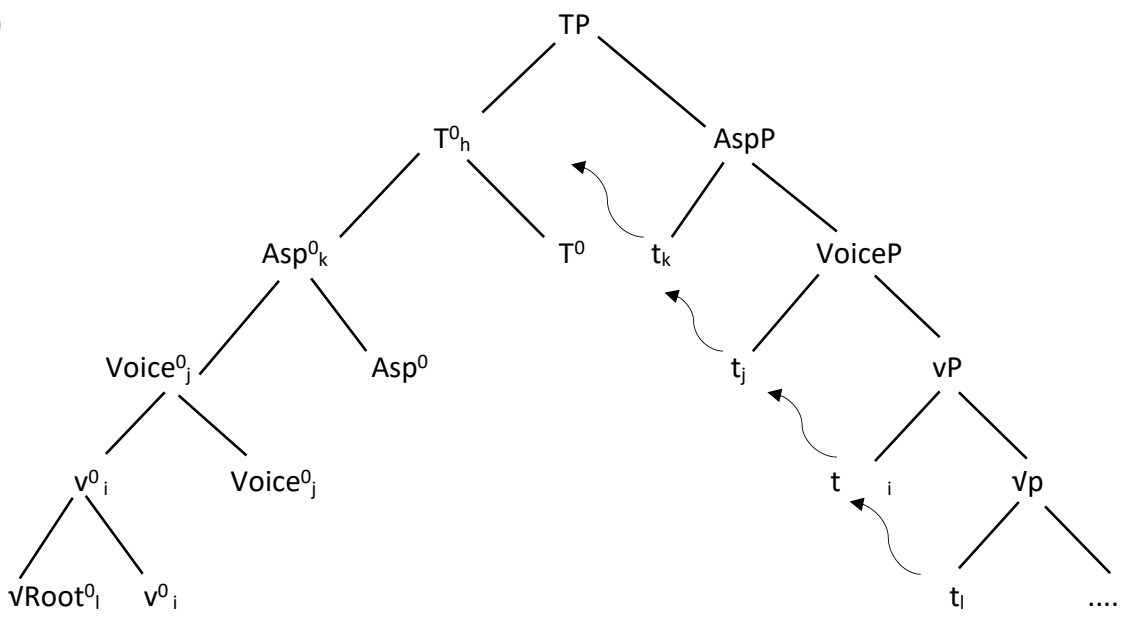

${ }^{\frac{172}{2}}$ The positioning of the exponent of the head as a suffix/prefix is due to information associated with the exponent and not a morphosyntactic property (see below). 
Three important operations are needed to derive the verbal surface structure of Romance verbal forms. Two of them insert ornamental ${ }^{13}$ morphological pieces such as AGR (Halle \& Marantz 1993, Bobaljik 2000) and Thematic Vowels (Oltra-Massuet \& Arregi 2005). The third prunes nodes with non-overt exponents.

As proposed in Calabrese (2019), the rule in (33) inserts AGR. The two rules in (34a) and (34b) insert Thematic Vowels (TV) in Italo-Romance verbal forms. One further rule adjoins a TV to $\mathrm{V}^{0}$ (see (34a)). It applies early in the derivation before VI (and the subsequent pruning operations discussed below). Another rule of TV insertion applies after VI and pruning operations and adjoins a TV only to overt functional heads (34b):

AGR-insertion:

Given a Complex $X^{0}$ not including inherent phi-features, adjoin $A G R_{v}$ to its highest $\mathrm{X}^{0}$ (to be revised later).

TV-insertion:

a. $\quad v^{0} \rightarrow$<smiles>OCN[AlH2]</smiles>

(it applies before VI)

b. $\mathrm{X}^{0} \rightarrow$

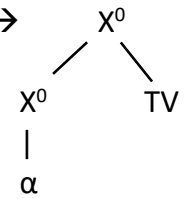

(it applies after $\mathrm{VI}$ and pruning, if $\alpha$ is an overt exponent )

So before VI, (33)and (34)a) apply in the case of complex head structure in (32):

\footnotetext{
저구

${ }^{13}$ As pointed out by Embick \& Noyer (2007: 305), "while all morphemes and interpretable features are present at $\mathrm{PF}$, not all morphemes that are found at PF are necessarily present in the syntactic derivation. Specifically, depending on language-specific well-formedness requirements, certain morphemes are added at PF. Such morphemes are never essential to semantic interpretation, since the derivation diverges onto PF and LF branches prior to the insertion of these morphemes. Thus, we speak of the reflexes of any morphemes inserted at PF as being 'ornamental': they merely introduce syntactico-semantically unmotivated structure and features which 'ornament' the syntactic representation." In other words, ornamental means that they do not have syntactico-semantic functions or content.
} 


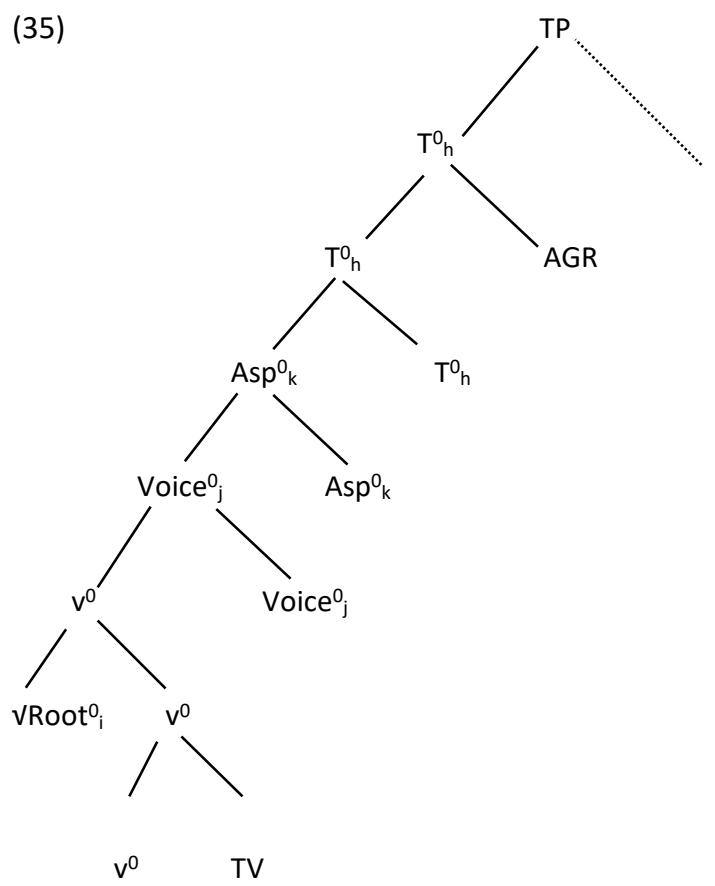

The complex head in (35) is the basic verbal structure of Italian generated by head movement before $\mathrm{Vl-insertion.} \mathrm{It} \mathrm{is} \mathrm{an} \mathrm{agglutinative} \mathrm{structure,} \mathrm{i.e.,} \mathrm{a} \mathrm{cumulation} \mathrm{of} \mathrm{morpho-}$ logical nodes. However, in Italian, functional categories such as aspect, tense and mood are no longer represented as independent morphological pieces as in Latin (cf. laud-avi-s-se-mus 'praise.PLUPRF.SBJV.1PL '). On the contrary, a single morpheme appears for the string Mood+T+Past. Instead of assuming Halle \& Marantz's (1993) fusion to account for the merging of these nodes, Calabrese (2019) proposes cyclic pruning of nodes with non-overt exponence followed by upward docking of the features that consequently become floating, as discussed below. ${ }^{14,15}$ The rule is given in (36):

\footnotetext{
쥬]

${ }^{14}$ Pruning was originally proposed by Embick (2010) only for non-overt category defining nodes. Following Christopolous \& Petrosino (2017) and Christopoulos (2018), Calabrese (2019) extended it to all types of non-overt category nodes and reformulated it as in (36).

${ }^{15}$ It does not follow that all non-overt exponents are automatically pruned. There could be exceptions (see Calabrese 2019).
} 
(36)

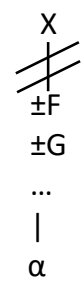

if $X$ is a terminal node containing the features $[ \pm F, \pm G, \ldots]$ and $\alpha$ is phonologically null exponent.

After pruning, the category $X$ is not deleted; it becomes floating and is merged with an adjacent higher terminal node, if there is one. ${ }^{16}$ This results in the fusion of the two terminal nodes where terminal node fusion is always triggered by this pruning operation. This operation applies cyclically right after the insertion of a null exponent during cyclic vocabulary insertion in phonological spell out. The delinked floating category can then attach only to the higher adjacent terminal node since the lower adjacent node has already undergone $\mathrm{VI}$, and therefore can no longer be assigned morphological features. This is shown in (37), where $\Phi_{1}$ and $\Phi_{2}$ are exponents, and $\Phi_{2}$ is phonologically empty: ${ }^{17}$

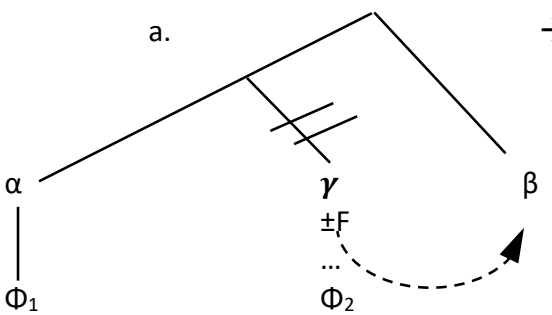

$\rightarrow \quad b$

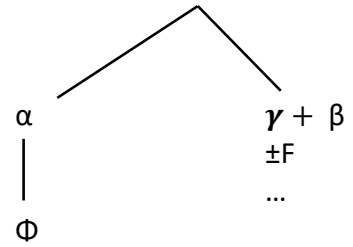

The pruning operation in (36) radically simplifies the phonological realization of morphosyntactic structures, and accounts for the convergence of possibly complex morphosyntactic structures and their possibly simpler PF surface shape. Consider the case of the Italian imperfect indicative amavate 'you.PL were loving'. Given the VIs in (38), cyclic VI followed by pruning and feature docking will generate the morphosyntactic structure in (39) where all the verbal functional nodes are fused together - in cyclic steps, due to the cyclic nature of VI insertion, an example of fusional morphology:

\footnotetext{
त्]?

${ }^{16}$ Another possibility is to assume that after pruning, it is not the category that becomes floating but actually its features, which eventually dock onto the adjacent terminal node.

${ }^{17}$ Unattached floating features are eventually deleted but only at the end of phonological spell out, so they can play a role in triggering morpho-phonological rules such as ablaut processes.
} 
(38)
a. $\varnothing<-->v^{0}$
b. $\varnothing<-->$ Voice $^{0}$
c. $\varnothing<-->[\text {-perfective }]_{A S P} 0$
d. $\varnothing<-->[+ \text { past }]_{T} 0$
e. /-v-/ <--> [-perfective, + past $]_{\text {Mood } 0}$

(39)

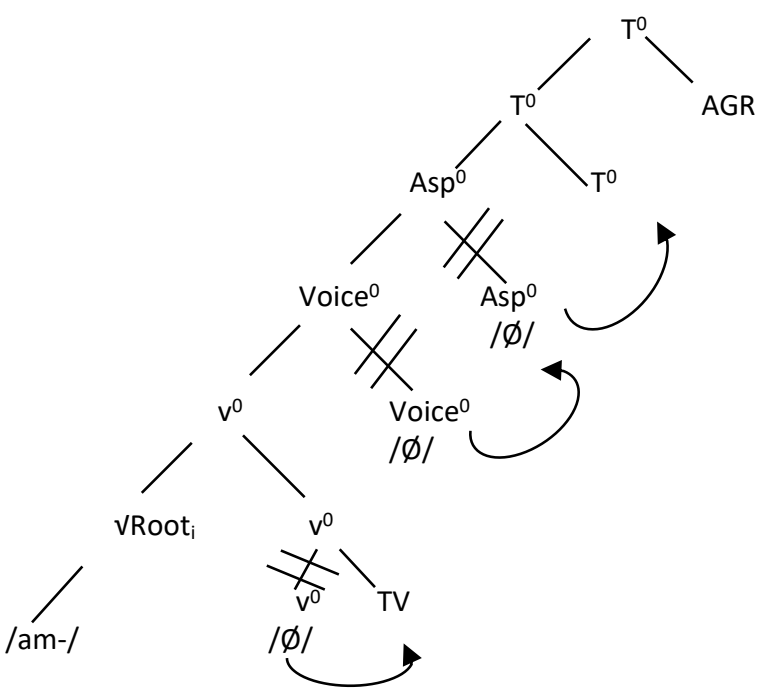

At this point due to the cyclic application of (38e), the exponent /-v-/ is inserted as follows:

(40)

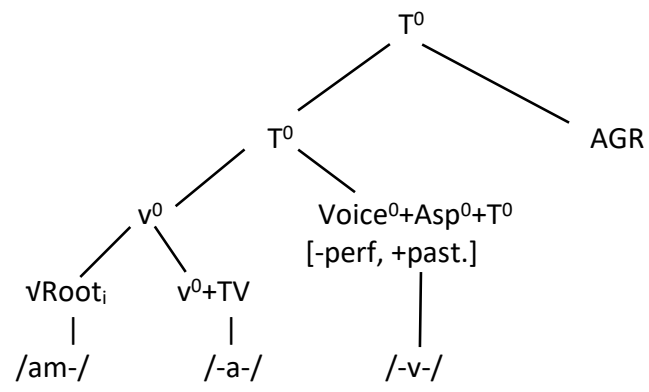

The TV insertion rule (34b) applies, and (41) is generated. For simplicity, we replace the complex fused [ Voice $\left.^{0}+\mathrm{Asp}^{0}+\mathrm{T}^{0}\right]$ head with $\mathrm{T}^{0}$ : 
(41)

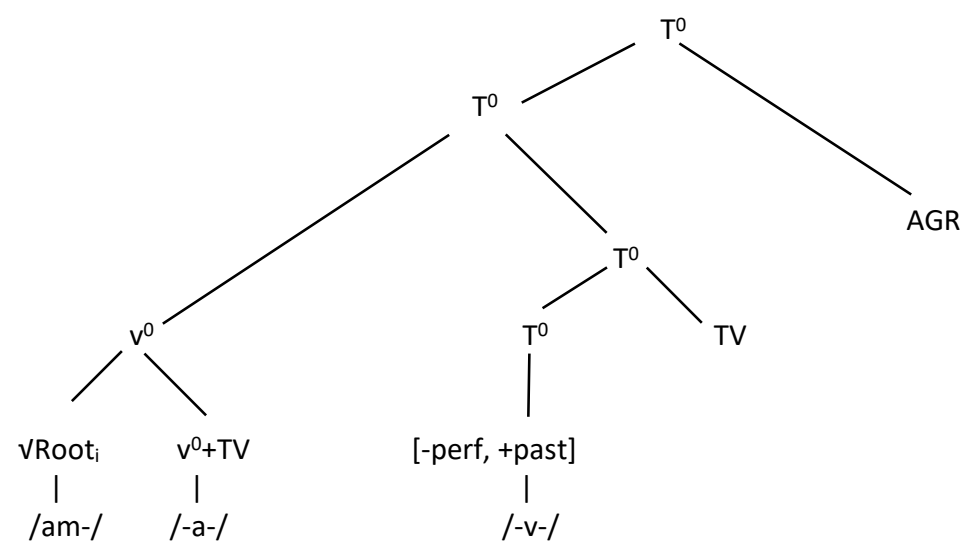

The final application of Vocabulary Insertion for TV and AGR will generate (42):

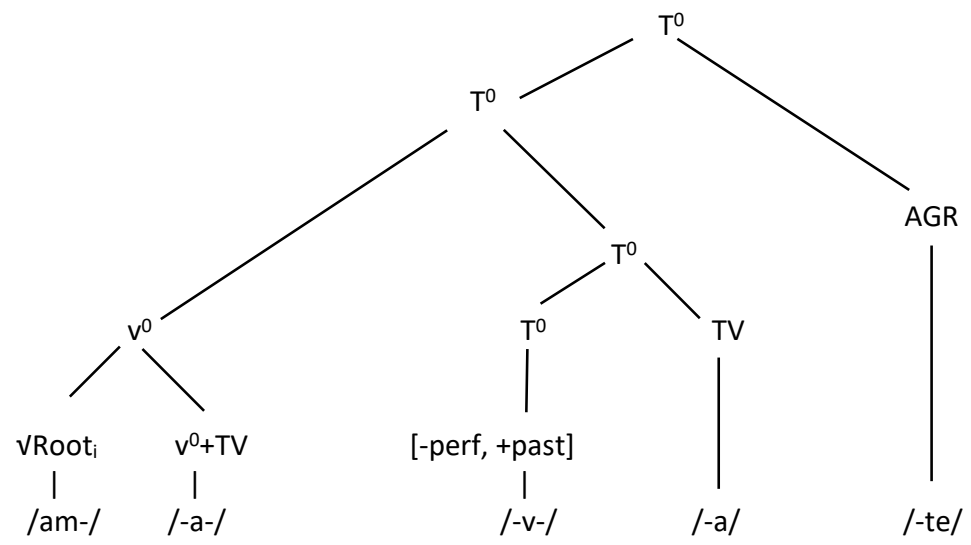

If verbal synthetic forms are due to the cyclic application of head movement which is able to convert the extended functional projection of a verb into a single complex $\mathrm{X}^{0}$ (i.e., a single word involving a root plus affixes), one can plausibly assume that, in contrast, periphrastic verbal forms - in which similar verbal extended functional projections are broken into different complex $\mathrm{X}^{0}$ (i.e. different words, auxiliaries and other verbal morphological pieces) - are due to the failure of the application of this operation to certain functional heads. In fact, this approach to periphrasis formation, which was at first formulated in Embick (2000) has been more recently fully developed by Bjorkman (2011), 
Pietraszko (2016), Fenger $(2018,2020)$ and Calabrese (2019). ${ }^{18}$ In Bjorkman and Pietrasko's works, the failure of functional heads to combine with the verb is due to the action of certain nodes (or better the feature complexes of those nodes) as interveners (Rizzi 1990) in syntactic processes - such as Agree ${ }^{19}$ - that lead to head movement. For example, the $v$-complex may not raise to Tense because (marked) aspect features intervene for the tense feature to be agreed with and checked. In Calabrese's model, in contrast, the failure of head movement is formalized in terms of morphological filters disallowing combinations of functional head features: movement is blocked if such combination may be generated. Fenger proposes that head movement may be blocked by phasal boundaries such as that between the verbal thematic complex which include Aspect and the higher T-C complex (see Bošković 2014, Wurmbrand 2017) - some form of phasal extension would be required to account for the cases where movement crosses these boundaries.

A thorough discussion, comparison and selection among these different theories is far beyond the goals of this paper. What matters for us here is that periphrasis is the result of blocking of head movement. A simple way of implementing this, without taking a stand with respect with above mentioned theories, is to propose that head movement ${ }^{20}$ from one head position in the extended functional verb projection to the one directly higher up may be parametrized with a parameter allowing or not allowing movement from this position. If higher up movement is blocked, the complex $X^{0}$ head that was cyclically contructed up to that point remains stuck there. This leads to a periphrastic formation in which the extended functional projection is split in at least two $\mathrm{X}^{0}$ complexes-words: a lower one, i.e, blocked $X^{0}$ complex, and a higher one including the higher functional heads of the projection. The head movement parameters may have their deeper grounds in the theories mentioned above, e.g., they may be motivated by

\footnotetext{
??

${ }^{18}$ An obvious advantage of such approaches over purely lexical ones that assume that periphrastic formation is just due to paradigmatic gaps (see Kiparsky 2004 for example) is thatthe periphrastic structure, and the subsequent formation of auxiliaries, follows the hierarchial functional structure: it is expected that when there is ahigher and lower head, the lower head will end up on the verb, whereas the higher head ends up on the auxiliary.

${ }^{19}$ In Bjorkman's system this is done via a version of Agree (Chomsky 2000, 2001), namely Upward Agree (see Merchant 2011, a.o.); in Pietraszko's system this happens through a type of selection, similar to cyclic agree (Béjar \& Rezac 2009).

${ }^{20}$ Here we are dealing only with head raising. The same blocking could also occur with head lowering, which is not considered here.
} 
morphological constraints on combinations of marked morpho-syntactic features as in Calabrese's approach, and essentially also, in Bjorkman's and Pietraszko's one, or may be the effect of the presence of phasal boundaries as in Fenger's approach, but choosing what are their deeper bases will not be an issue here.

Thus, given the basic syntactic structure in (43), we assume that UG includes a parameter blocking head movement of the Asp [+Prog] head. Therefore, when a complex head reaches this position, it can no longer be head raised to $\mathrm{T}^{0}$ as in (44):

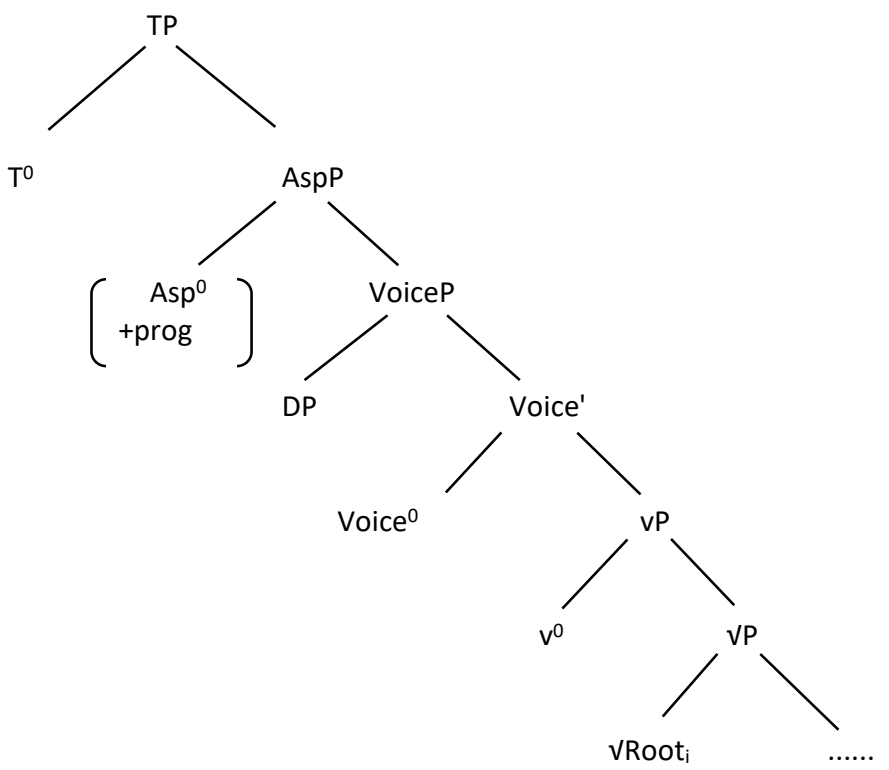


(44)

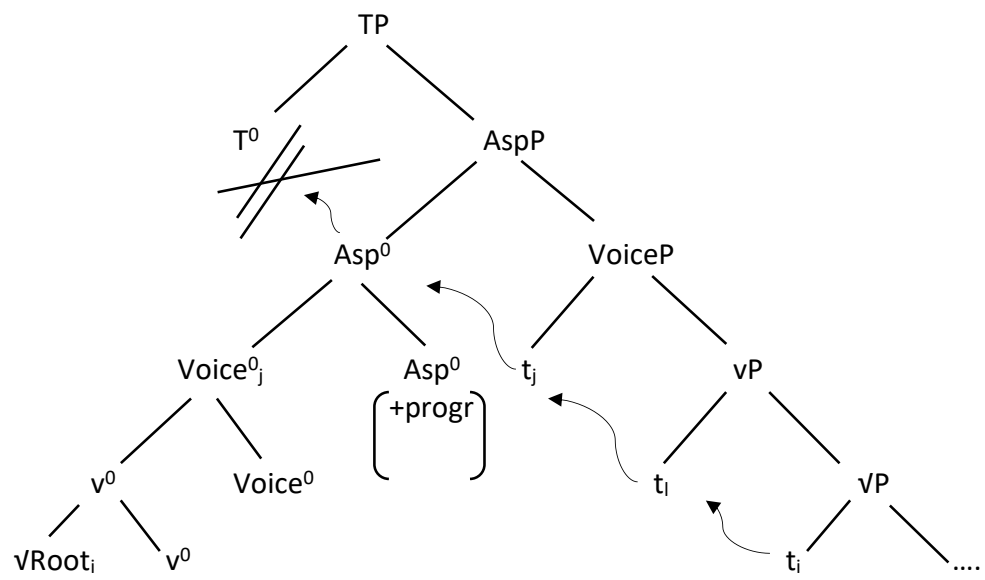

The lower complex $\mathrm{X}^{0}$ constituent undergoes pruning and $\mathrm{TV}$ and $\mathrm{AGR}_{\mathrm{v}}$ insertion as in (45):

(45)

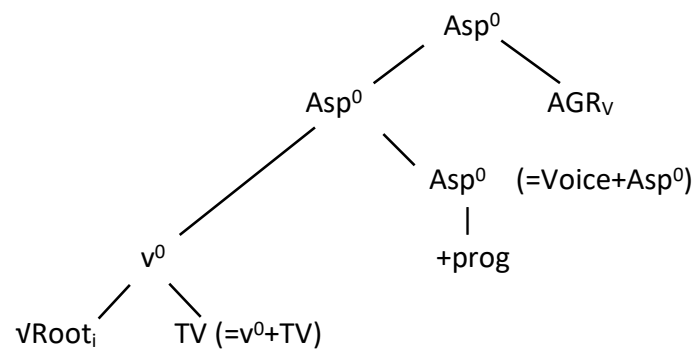

We assume that the gerund marker /-ndo/ cannot be decomposed morphologically. It is a single piece like the suffixal /-re/ of infinitive forms (i.e. ama-re, perde-re, etc.; see below). This assumption requires the two VIs in (47) and (48). (46) inserts a non-overt $\varnothing$ for $[+ \text { prog }]_{A s p}{ }^{0}$. This triggers pruning of this node and feature floating to the higher AGR, where /-ndo/ is inserted as in (47):

(46)

PROGRESSIVE VI

$\mid \varnothing /<-->[+ \text { prog }]_{\text {Asp }}{ }^{0}$

$$
\text { /-ndo/ <--> }\left[+\operatorname{prog}_{\text {Asp }}{ }^{0}+\text { AGR }\right]
$$


(48)

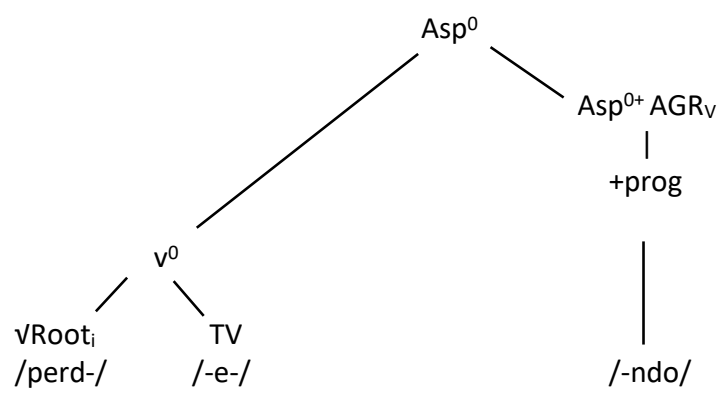

Let us now consider the higher constituent in the structure.

(49)

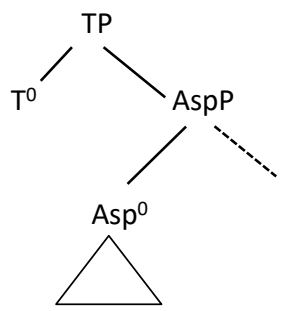

The functional head $\mathrm{T}^{0}$ is not adjoined to a root or to a complex $\mathrm{X}^{0}$ containing a root. Therefore, this constituent is in violation of (28). A dummy root - the AUX root - is hence inserted as a "holder" for these functional heads (Bjorkman 2011):

(50)

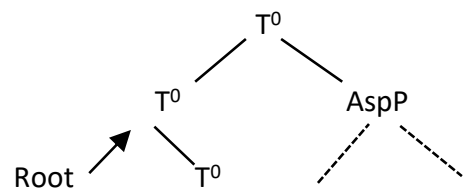

The auxiliary in this case is stare (lit. 'stay'). One problem is establishing whether the inserted root in this case is /sta-/or /st/ + TV /-a-/. If the root is /sta/, the independently motivated rule of hiatus resolution in (51) would account for forms such as sto ' $1 \mathrm{sg}$ ' (i.e., $/$ sta/+ /-o/ $\rightarrow$ sto):

$$
\mathrm{V} \rightarrow \varnothing / \ldots
$$

The 1st person plural present form stiamo, however, shows that the vowel of /sta-/ is actually a thematic vowel insofar as /-ya-/ is the expected allomorph of the thematic vowel in the 1st person plural (see Calabrese 2019). If the stem were /sta+TV/ we would expect sta-ya-mo in this case as in tra-ya-mo, tra-e-te from tra-e-re 'pull'. 
Note now that there is no $v^{0}$ in the structure in (50) and that therefore there should not be a $v^{0}$ TV. In fact, in many Italian dialects, the thematic vowel is missing in auxiliaries. See for example the following cases that compare the use of avere as a lexical verb and as an auxiliary:

(52) Lexical and auxiliary have in Sicilian and in Neapolitan

$\begin{array}{lll}\begin{array}{l}\text { a. Sicilian } \\ \text { lexical aviri }\end{array} & & \text { auxiliary } \\ \text { aju } & & \text { aju } \\ \text { a(i) } & a(i) \\ \text { avi } & a & \text { amu } \\ \text { avemu } & & \text { ati /atu } \\ \text { aviti } & \text { annu } \\ \text { annu } & \\ \text { b. Neapolitan } & \\ \text { lexical avé } & \text { auxiliary } \\ \text { aggio } & \text { aggiu } \\ \text { aie } & \hat{e} \\ \text { ave } & \text { a } \\ \text { avimmo } & \text { amme } \\ \text { avite } & \text { ate } \\ \text { àveno } & \text { anno }\end{array}$

However, in standard Italian there is indeed a thematic vowel in auxiliary avere, so in avete/avevate /av-/ is the root and /-e-/ is the expected thematic vowel, which can also be observed when avere occurs as a main verb:

avete/avevate una bella casa (av-e-te/av-e-v-a-te)

'you have/you had a beautiful home'

To account for what happens in this case, Calabrese $(2019,2020 a)$ proposes that this is an instance of an abstract morphomic condition. Abstract morphomic conditions, according to him, introduce ornamental nodes such as Thematic Vowels but also what appears to be syntactically void functional heads. They are the ways in which the outcomes of analogical, or purely morphological, changes are integrated in the PF derivation, and the means by which abstract syntactic structures are converted into surface morphophonological forms where one finds pieces that do not have a true syntactic motivation. In the case of the auxiliaries, the morphological structure condition in (55) formally generalizes verb structure to AUX - a purely morphological change - by inserting a 
syntactically void $v^{0}$ node and therefore the relevant TV. It holds in Italian but not in the Italo-Romance varieties in (52):

$$
\text { AUX } \rightarrow
$$

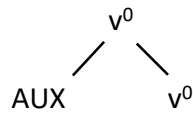

We can now propose that the auxiliary selection rule is that in (55):

$$
\mathrm{AUX} \rightarrow / \mathrm{st}-/ / \text { AspPerf }^{[+\mathrm{prog}]}
$$

The application of (54) to the complex head in (50), as well as the insertion of AGR and TV, and the pruning of null $v^{0}$ due to its null status, will generate (56) in the case of the imperfect forms:

(56)

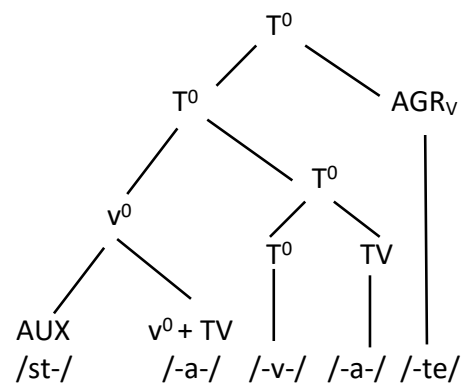

The full periphrastic construction is hence that in (57): 
(57)

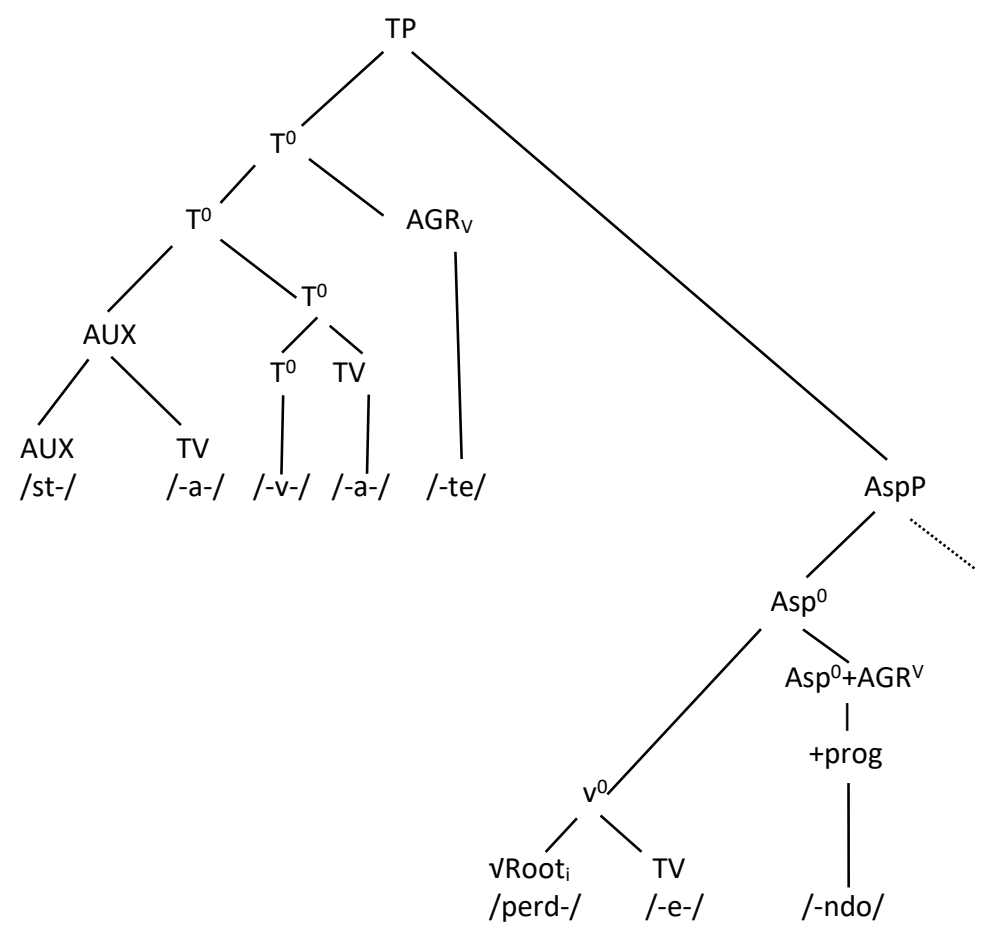

Alternative progressive periphrastic constructions characterized by an infinitive introduced by a simple or complex preposition and possibly a different auxiliary such as be ('be at', 'be with', 'be in the middle/midst of ', 'do', 'be in the course of', 'be on the way', 'now', 'hold', 'engaged/busy in', 'during', etc.), can be derived in the same way if one assumes that the connecting preposition (the linker) is inserted by the rule in (58) as an instance of ornamental morphology and is therefore devoid of any syntactic and semantic content (see also fn. 1). The structure for the (substandard) Italian progressive periphrasis stavate a perdere (you.PL were at losing, 'you were losing') is shown in (59) see below (cf. § 3.2) on the status of infinitives:

(58)

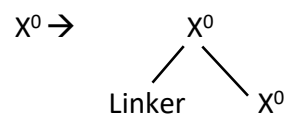


(59)

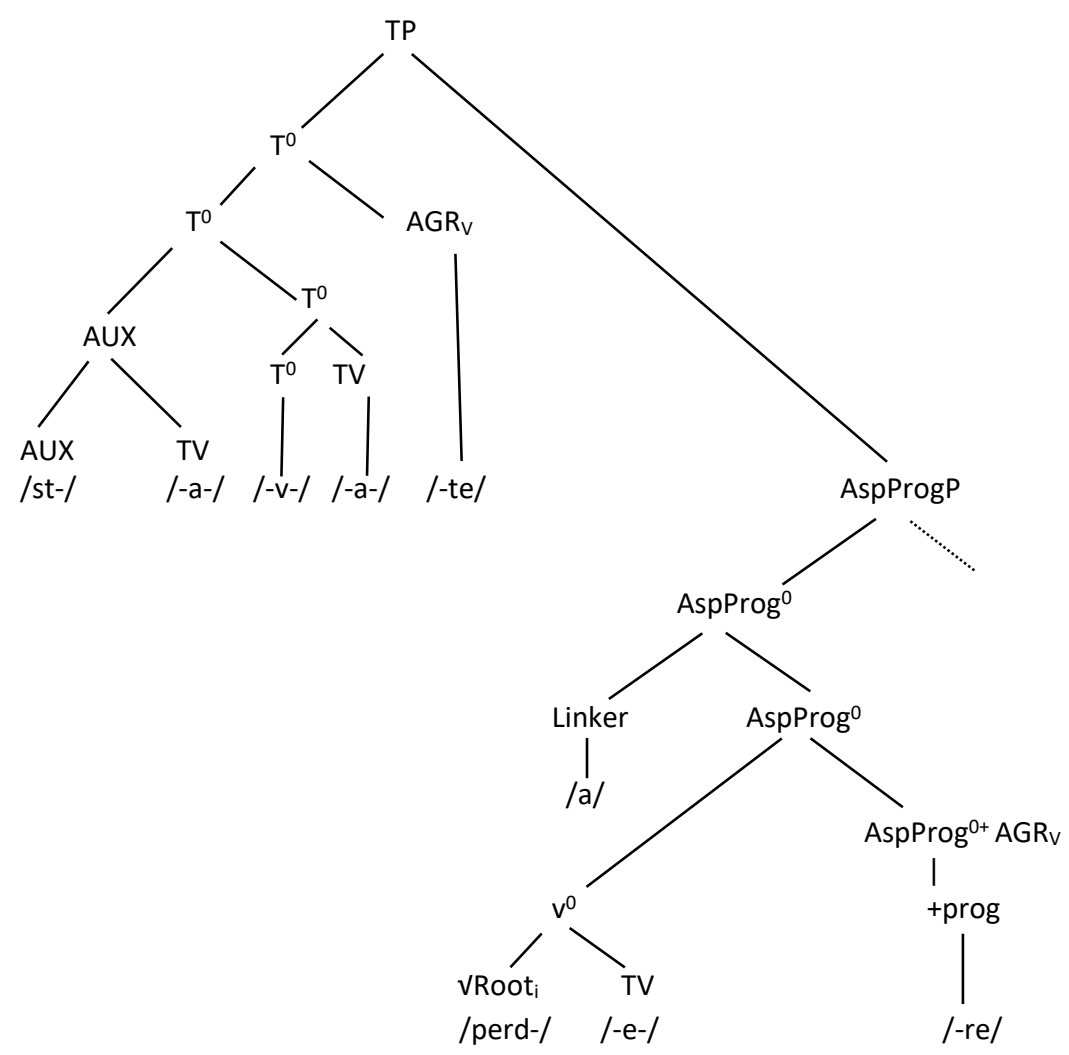

We assume that the Salentino synthetic progressive forms in (60) simply arise from setting the parameter allowing/disallowing head movement of [+progressive $]_{A s p} 0$ in this variety. They can then be derived through full cyclic application of head raising (no blocking) with the crucial assumption that the exponent /sta-/ of the progressive is marked as being antitropal, i.e., it appears as a prefix instead of the morphosyntactically expected suffix (cf. (60)):

$$
\begin{aligned}
& \text { sta-kumpramu / sta-kumpravamu } \\
& \text { stay-buy.PRS.1PL stay-buy.IMP.1PL } \\
& \text { 'we are buying' / 'we were buying' }
\end{aligned}
$$


(61)

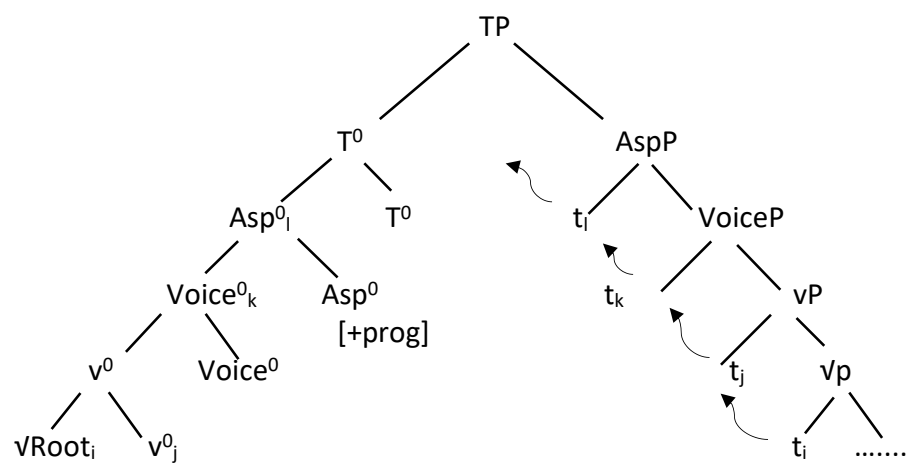

(62)

$$
\text { /-sta-/non-homotropal }<-->[+ \text { prog }]_{A s p} 0
$$

Insertion of the relevant TV and pruning of null exponents will generate the surface structure in (63):

(63)

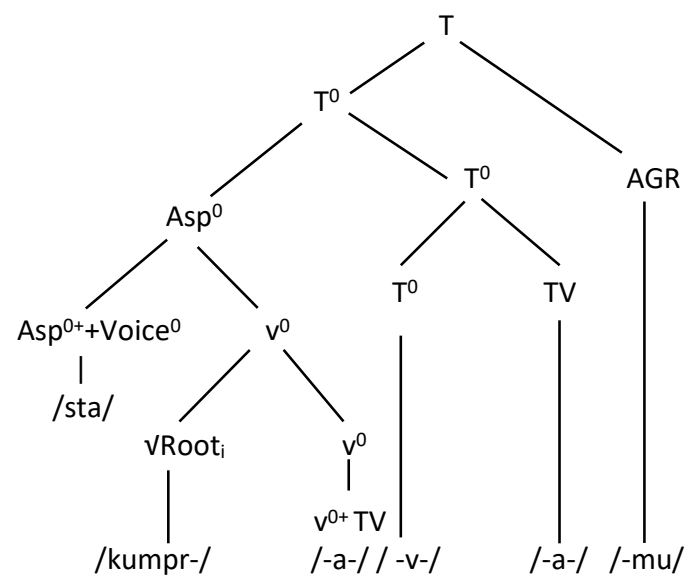

\subsection{A morphosyntactic analysis of the Infinitival MVC}

Following the model developed above, we can now provide a more explicit morphosyntactic analysis of Infinitival MVC constructions with restructuring. Consider (64): 
(64) Lo andavate a mangiare. (Italian)

it = go.IMP.2PL to eat.INF

'You were going to eat it.'

The sentence in (64) has the basic syntactic structure in (65) in the model developed here. Here V1 is a functional head in the Asp field (cf. $\S 2$ ), which we label And $^{0}$ :

(65)

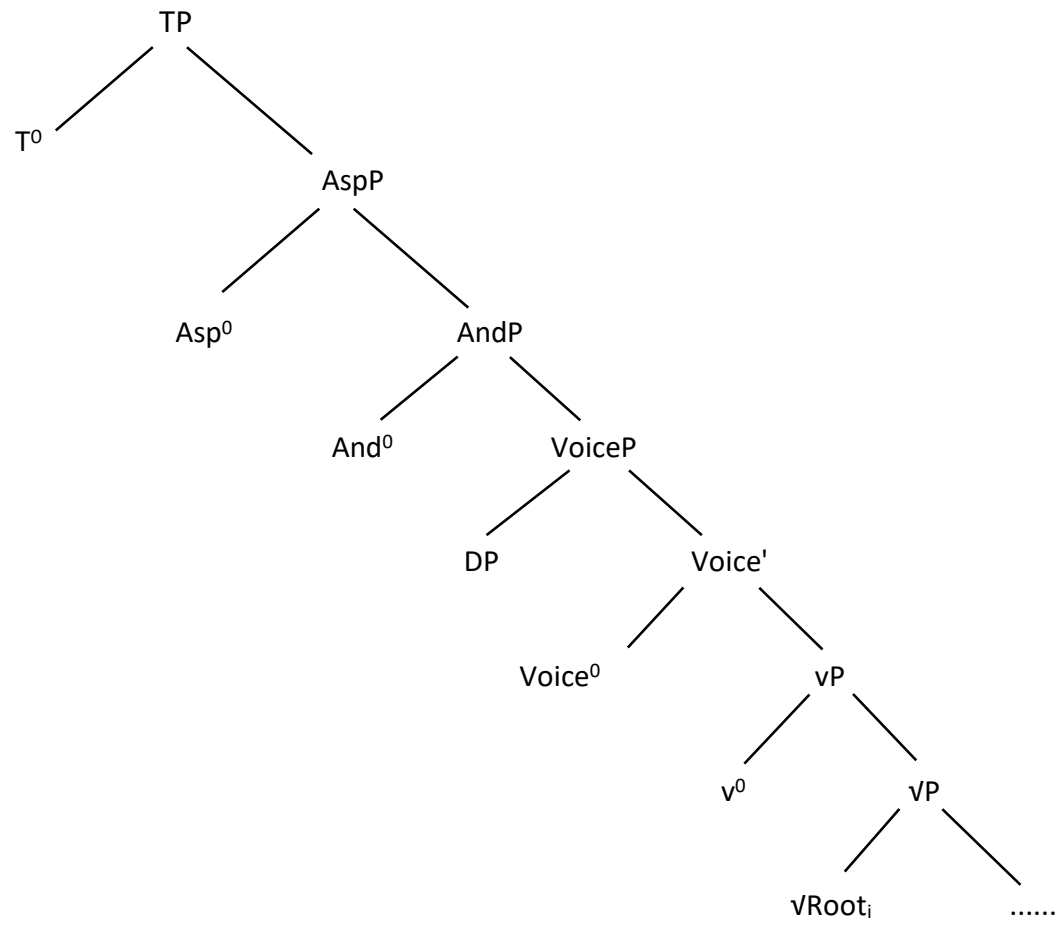

There are two issues to be addressed here before we analyse how (65) is converted to the surface Infinitival MVC in (64). First of all, we need to examine the connecting element /a/ and its morphosyntactic status. As proposed above (cf. § 2), we assume that this element is a linker that is inserted as an instance of ornamental morphology by the rule in (58) repeated as (66). It is thus devoid of any syntactic and semantic content.

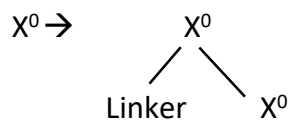


Secondly, we need to understand why V2 is characterized by infinitival morphology: what is the morphological nature of the infinitive? The infinitive, with the gerund, is by definition the "uninflected" verbal form and occurs in a wide variety of embedded constructions. Stowell (1982) suggested a basic distinction between future infinitives like that in (67a) (i.e., constructions in which the embedding predicate requires that the complement be "unrealized" at the time of the matrix event) and propositional infinitives like that in (67b) and (67c) (i.e., constructions in which the embedding predicate does not presuppose or assert anything about the temporality of the embedded event):

a. Carlo ha deciso di leggere quel libro domani.

Carlo has decided of read.INF that book tomorrow

'Carlo decided to read that book tomorrow.'

b. Giorgio ha asserito di essere molto bravo.

Giorgio has stated of be.INF very good

'Giorgio claimed to be very good.'

c. Ritengo Maria essere molto bella.

believe.1SG Maria be.INF very beautiful

'I believe Maria to be very beautiful.'

Wurmbrand (2014) has shown that future infinitives are tenseless but involve a syntactically present future modal element, whereas propositional infinitives are TPs that involve a temporal argument corresponding to the attitude holder's Now. She also adds the category of simultaneous nonattitude infinitives for those that are found in raising and restructuring verbs which can be AspPs if they include embedded (im)perfective or are bare vPs or VP.

(68) Sandra sembra parlar bene il francese. (infinitive with raising verb) Sandra seems speak.INF well the French

'Sandra seems to speak French well.'

(69) a. Mario lo può leggere domani. (infinitive with restructuring verbs)

Mario it= can.3sG read.INF tomorrow

'Mario can read it tomorrow.'

b. Giorgio lo deve comprare subito.

Giorgio it= must.3sG buy.INF immediately

'Giorgio must buy it immediately.'

c. Giovanni lo ha cominciato a cucinare ieri.

Giovanni it= has started to cook.INF yesterday

'Giovanni started cooking it yesterday.' 
d. Sandro lo avrebbe voluto poter cominciarea fare subito. Sandro it=have.COND.3SG wanted can.INF start.INF to do.INF immediately 'Sandro would have liked to be able to sart doing it immediately.'
a. matrix $\vee[C P$ [TP/FutlP [AspP [vP [VP]]]
b. matrix $V$
[TP/FutIP
[AspP
[vP [VP]]]
c. matrix $\mathrm{V}$
[AspP [vP [VP]]]
d. matrix $\mathrm{V}$
[vP [VP]]
e. matrix $\mathrm{V}$
[VP]

Importantly, for all constructions, Wurmbrand also showed that the different temporal properties of the infinitive do not correlate with a difference between control and $\mathrm{ECM} /$ raising. It follows that there is no syntactic functional verbal element, or other syntactic property, that can account for the surface distribution of the infinitive. An alternative, however, is to assume that this distribution is simply determined in the morphological component. Note in particular that all of the infinitival constituents in (70) share the property of being independent morphological words, specifically a verbal complex $X^{0}$. As proposed in Calabrese (2019), an important feature of all verbal complexes $X^{0}$ is that they are assigned an AGR node which is adjectival in participle forms - analysed as complex Asp ${ }^{0}$ heads in Calabrese (2019) - but is otherwise verbal, where verbal $A G R_{V}$ probes for person and number features, and adjectival $A G R_{A d j}$ probes for gender and number features (and case features in languages with overt morphological case). The rule for AGR insertion proposed in that work is the following:

$$
\begin{aligned}
& \text { Given a MP unit } U \text { containing } v^{0},\left(M P \text { unit }=\text { Complex } X^{0}\right) \\
& \text { a. Adjoin } A G R_{A d j} \text { to its highest } X^{0} \text { if } X^{0} \text { is } A s p^{0} \\
& \text { Otherwise: } \\
& \text { b. Adjoin } A G R_{V} \text { to its highest } X^{0}
\end{aligned}
$$

We propose that the infinitive is the morphological realization of the $A G R_{V}$ and that it is therefore sensitive to $A G R_{V}$ features. In particular, we propose that the AGR properties of inflected verbal forms are associated with the feature [+pronominal], which triggers explicit morphological marking of phi-features. If the AGR is [-pronominal], in contrast, it lacks explicit marking of phi-features, and can co-occur with anaphorically-bound PRO subjects, with overt NPs, and with subjectless structures. The [-pronominal] AGR is realized as the infinitive: ${ }^{21}$

\footnotetext{
]?]?

${ }^{21}$ Here we are assuming that the exponent /-re/ of the infinitive cannot be further decomposed. See Cardinaletti \& Shlonsky (2004) for a different view.
} 


$$
\text { /-re/ <--> [-pronominal }]_{A G R}
$$

The distribution of infinitives can be captured if one assumes that the presence of [+pronominal] AGR is associated with the presence of a deictic tense, as stated in (73). The feature [-pronominal] occurs as a default when Tense is non-deictic, i.e., anaphorically dependent on the Tense of the matrix verb, or when Tense is simply missing as in the future infinitives or in constructions with restructuring: ${ }^{22}$

$$
\text { Deictic Tense } \rightarrow[+ \text { pronominal }]_{\mathrm{AGR}}
$$

Infinitives therefore have a morphosyntactic structure such as that in (74), where $X^{0}$ is the highest functional element of the constituents in (70), and can range over different non-Asp ${ }^{0}$ heads. This head is eventually fused into a single node with AGR as in the finite present counterpart (see (74)).

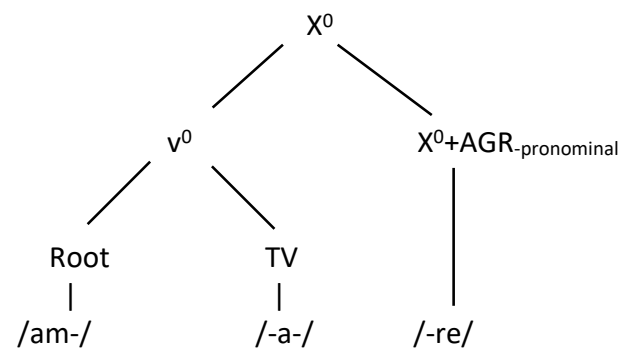

We now finally have all of the machinery to deal with the Infinitival MVC deictical tense. These costructions have all the same basic syntactic structure in (65) where And ${ }^{0}$ selects a VoiceP constituent. As a functional head, And ${ }^{0}$ is targeted by $\mathrm{m}$-word. We propose, however, that head movement of the complex head $\mathrm{And}^{\circ}$ is blocked (as indicated by the sign //) due to the relevant parameter setting as in (75). ${ }^{23}$

?]? sume the presence of a TP:

(i) a. L' aver Mario vinto quel concorso il mese scorso è una bella cosa. the have.INF Mario won that contest themonth last is a beafutiful thing 'Mario's winning that contest last month is a beautiful thing.'

b. L' aver Mario bevuto tutto il vino ieri è un grosso problema. the have.INF Mario drunk all the win yesterday is a big problem 'Mario's drinking all the wine yesterday is a big problem.'

${ }^{23}$ See Calabrese (2019) for an account of this blocking. Alternative accounts of auxiliary formation can be found in Bjorkman (2011) and Pietraszko $(2016,2018)$. 
34 Silvio Cruschina \& Andrea Calabrese

(75)

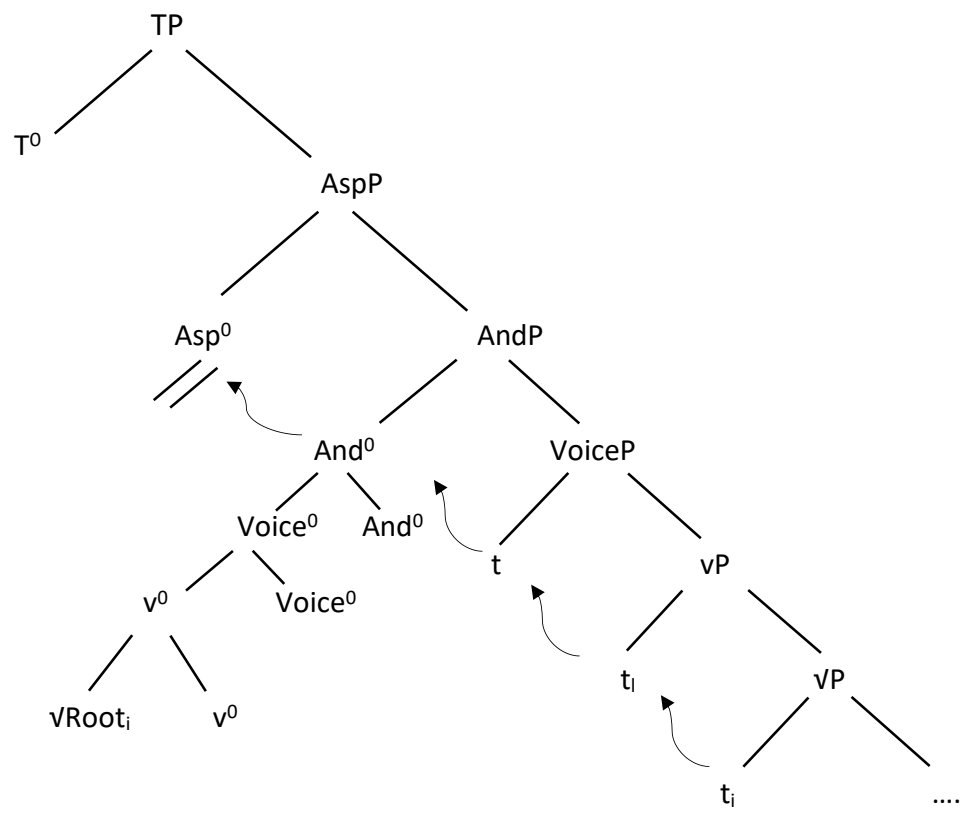

Let us consider the lower complex head in (75). TV and AGR insertion, pruning, and the operations discussed above account for the emergence of infinitive morphology:

(76)

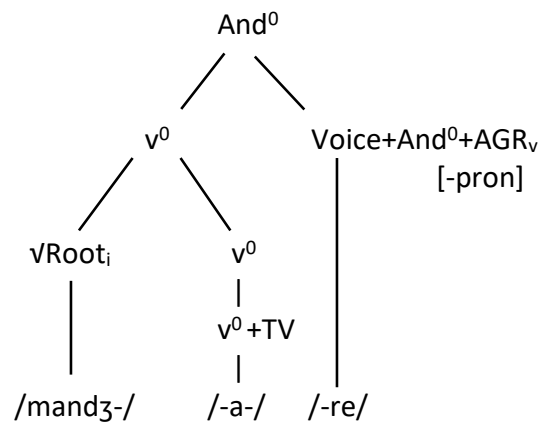

The linker /a/ is inserted as in (77): 
(77)

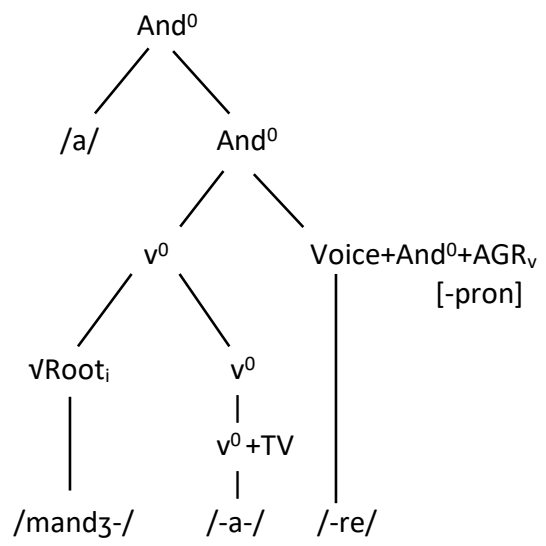

Let us then consider the top part of the structure in (77): Asp ${ }^{0}$ undergoes head movement to $\mathrm{T}^{0}$ as in shown in (78).

(78)

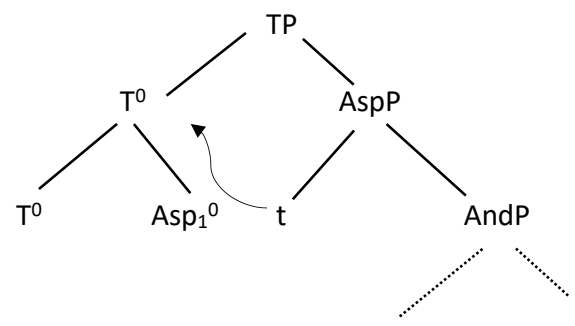

The resulting complex head lacks a root in violation of (28). A dummy AUX root is inserted. The shape of this AUX is determined by the rules in (79), which are sensitive to the different flavours of $\mathrm{And}^{0}$ (andare, passare, venire, etc.), which percolates upwards to the phrasal projection.
a. AUX $\rightarrow$ /AND-/24 /
AndPA
b. AUX $\rightarrow$ /pass-/ /
AndP $P^{P}$
c. AUX $\rightarrow$ /ven-/ /
AndPv etc.

??

${ }^{24}$ This is an abstract root showing the suppletive alternant/vad-/ in the present, otherwise /and-/. See Calabrese (2020b) for an analysis of root suppletion in andative constructions in Salentino dialect of Campi Salentina. 
Further $\mathrm{v}^{0}$, TV and AGR insertion, along with null node pruning and docking, generates the surface PF string in (80):

(80)

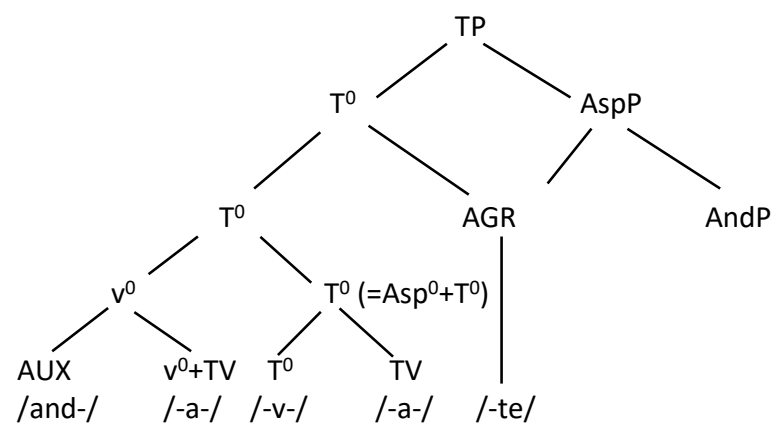

The full surface structure of (64) is displayed in (81): 


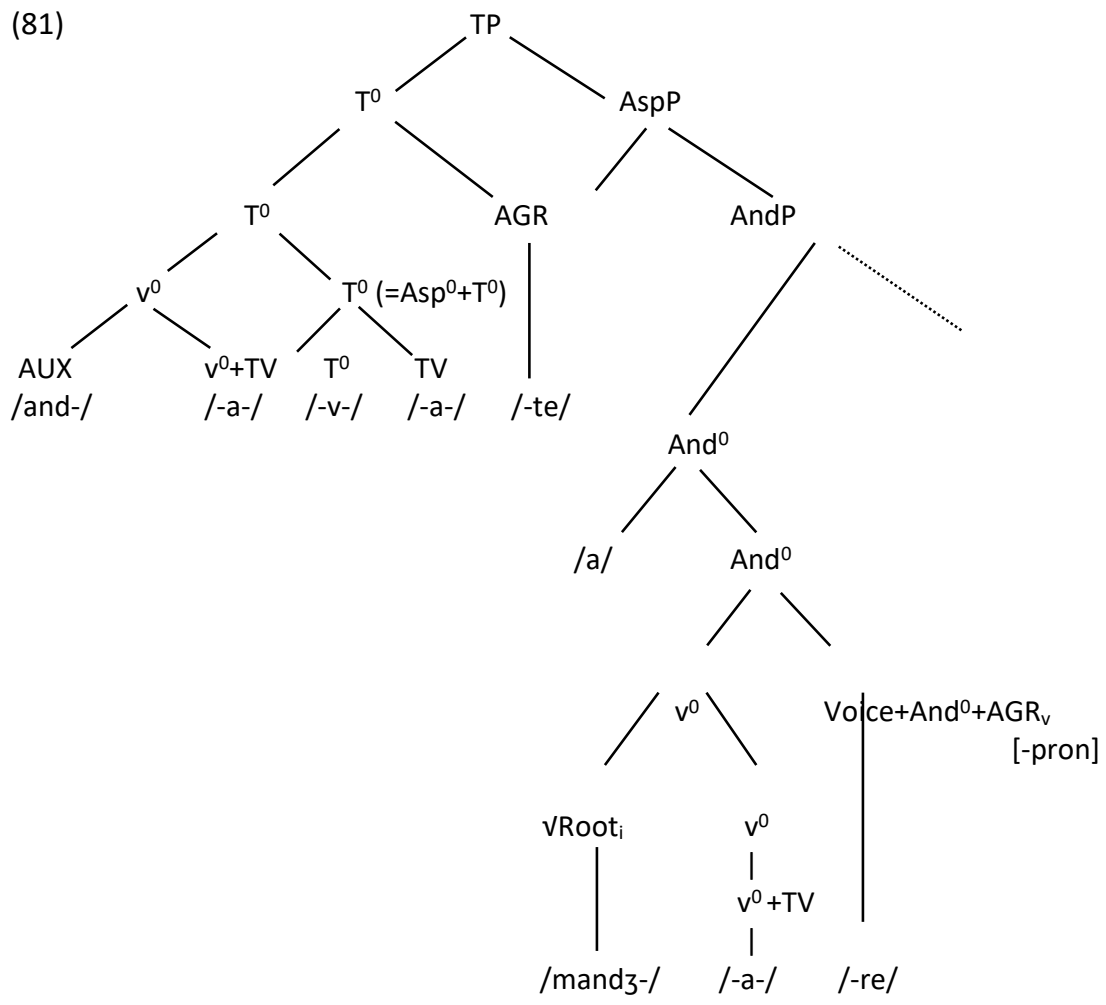

\section{Doubly Inflected Constructions}

Let us now consider, more specifically, the morphosyntactic patterns that characterize DICs. In some dialects, DIC exhibits a full paradigm, which is often subject to morphological reduction (cf. § 2): this happens in eastern Sicily (e.g. Modica) and Salento (see Manzini \& Savoia 2005, I: 689-697). In many southern Italian dialects (in western and central Sicily, as well as in some Barese dialects north of Salento), however, DIC features a defective paradigm (see Cardinaletti \& Giusti 2001, Cruschina 2013). We argue that defective paradigm of DIC in these dialects is also the outcome of an impoverishment process yielding a paradigm with a distribution that closely resembles the ' $\mathrm{N}$-pattern' described 
in Maiden $(2004,2005,2018) .{ }^{25}$ In the tables below, the shaded cells are those in which DIC is available: as we can see, DIC is not available with the 1st and 2 nd persons plural of the present indicative or with the 2 nd plural of the imperative, which all feature the allomorphic (arhizotonic) or suppletive roots. The same roots are employed in the imperfect, as well as in the rest of the paradigm, where DIC is systematically absent:

Table 1: The paradigm of viniri (vèniri) 'come' in Mussomeli, Sicily (V2= pigliari 'take')

\begin{tabular}{|c|c|c|c|c|}
\hline \multirow{2}{*}{\multicolumn{2}{|c|}{$\begin{array}{l}\text { vI'nIrI } \\
\text { ('venIrI) }\end{array}$}} & \multicolumn{3}{|c|}{ Mussomeli } \\
\hline & & $\begin{array}{c}\text { present } \\
\text { (indicative) }\end{array}$ & imperative & $\begin{array}{l}\text { imperfect } \\
\text { (indicative) }\end{array}$ \\
\hline \multirow{3}{*}{ SG } & 1 & 'viənnฮ a prjjo & & vi'niva \\
\hline & 2 & 'viəni a prjji & & $\begin{array}{c}\text { vI'nIVI } \\
\text { (vi'nivato) }\end{array}$ \\
\hline & 3 & 'veni a pijja & 'viənI/'venI (a) pijja & vi'niva \\
\hline \multirow{3}{*}{$\mathrm{PL}$} & 1 & *vi'niəmv a pijjamv & & vi'nivamo \\
\hline & 2 & ${ }^{*}$ VI'nItI a a pijjatı & & $\begin{array}{l}\text { vi'nivavo } \\
\text { (vI'nIVIVত) }\end{array}$ \\
\hline & 3 & 'viənnঠ a pijjanz & *vI'nItI (a) pijjatI & vi'nivanu \\
\hline
\end{tabular}

Table 2: The paradigm of passari 'come (by)' in Mussomeli, Sicily (V2= pigliari 'take')

\begin{tabular}{|c|c|c|c|c|}
\hline \multirow{2}{*}{\multicolumn{2}{|c|}{ pas'sarr }} & \multicolumn{3}{|c|}{ Mussomeli } \\
\hline & & \multirow{2}{*}{$\begin{array}{c}\text { present } \\
\text { (indicative) } \\
\text { 'passu a prjju }\end{array}$} & \multirow[t]{2}{*}{ imperative } & \multirow{2}{*}{$\begin{array}{c}\text { imperfect } \\
\text { (indicative) } \\
\text { pas'sava }\end{array}$} \\
\hline \multirow{3}{*}{ SG } & 1 & & & \\
\hline & 2 & 'passi I a prjji & & $\begin{array}{c}\text { pas'savi } \\
\text { (pas'savatv) }\end{array}$ \\
\hline & 3 & 'passa a pijja & 'passa (a) pijja & pas'sava \\
\hline \multirow{3}{*}{$\mathrm{PL}$} & 1 & *pas'samv a pijjamv & & pas'savamo \\
\hline & 2 & *pas'sati a a pijjatI & & pas'savavo \\
\hline & 3 & 'passanv a pijjanv & *pas'sati (a) pijjatı & pas'savano \\
\hline
\end{tabular}

?]?

${ }^{25}$ This is the most widespread defective paradigm in Sicily, but is apparently not the only possible distribution found on the island (see Di Caro 2018, 2019 for the patterns of variation). 
Table 3: The paradigm of ìri 'go' in Mussomeli, Sicily (V2= pigliari 'take')

\begin{tabular}{|c|c|c|c|c|}
\hline \multirow{2}{*}{\multicolumn{2}{|c|}{ pas'sarI }} & \multicolumn{3}{|c|}{ Mussomeli } \\
\hline & & \multirow{2}{*}{$\begin{array}{c}\begin{array}{c}\text { present } \\
\text { (indicative) }\end{array} \\
\text { 'vaju a prjju }\end{array}$} & \multirow[t]{2}{*}{ imperative } & \multirow{2}{*}{$\begin{array}{c}\begin{array}{c}\text { imperfect } \\
\text { (indicative) }\end{array} \\
\text { 'jivo }\end{array}$} \\
\hline \multirow{3}{*}{ SG } & 1 & & & \\
\hline & 2 & 'va a prijji & & 'jIfti \\
\hline & 3 & 'va a pijja & 'va (a) pijja & 'jI \\
\hline \multirow{3}{*}{ PL } & 1 & *'jamo a pijjamo & & 'jamo \\
\hline & 2 & *'jitr a a pijjatı & & 'jIftrvo \\
\hline & 3 & 'vannu a pijjanu & *'jitI (a) pijjatI & 'iaru \\
\hline
\end{tabular}

In the provinces of Bari (BA) and Brindisi (BR), DIC is found with a full paradigm in most dialects (e.g. Alberobello and Cisternino), but a defective DIC is also attested within the same area, as in the dialect of Conversano (Paolo Lorusso p.c., Manzini \& Savoia 2005, Andriani 2017):

Table 4: Full and defective paradigms in some Barese dialects

\begin{tabular}{|c|c|c|}
\hline \multicolumn{2}{|c|}{ FULL PARADIGM } & DEFECTIVE PARADIGM \\
\hline Alberobello (BA) & Cisternino (BR) & Conversano (BA) \\
\hline 'go + fetch' & 'go + play' & 'go' \\
\hline vókə ppìgghiə & vò ssòne & vek \\
vè ppìgghiə & vè ssùənə & ve \\
vè ppìgghiə & vè ssònə & ve \\
scì ppəgghiéimə & scì ssunémə & $\int \varepsilon m$ \\
scì ppəgghiéitə & scì ssunétə & $\int \varepsilon t$ \\
vàunə ppìgghiənə & vònə ssònənə & van \\
\hline
\end{tabular}

Crucially, the distribution of DIC in the dialect of Conversano is identical to that found in the Sicilian dialects, where DIC is not available with the 1st and 2nd person plural of the present indicative (i.e. the shaded cells).

At this point we need to account for two major properties of DICs: double inflection and the defective paradigm. As briefly mentioned above (cf. § 2), double inflection arises independently of restructuring. What is special about this set of constructions is the agreement within the extended VP. In other words, DICs involve the assignment of explicit pronominal agreement features to $\mathrm{V} 2$. We have already postulated the presence of an $A G R_{v}$ element in the V2 constituent: it is introduced by the rule in (71). As postulated earlier, this $A G R_{v}$ is usually assigned the feature [-pronominal] and is hence realized as an infinitive, due to the fact that the V2 constituent lacks a deictic (non-anaphoric) 
Tense (or lacks this node entirely) (see (70)). If we assume this, then the main feature that characterizes DIC is the fact that the V2 AGR is actually assigned the feature [+pronominal]. DICs thus display special morphological behaviour - a [+pronominal] $A G R_{v}$ in $\mathrm{V} 2$, that is, the rule in (82) which is characteristic of these dialects:

$$
\varnothing \rightarrow[+ \text { pronominal }] /[\ldots]]_{\text {And }}{ }^{+}+\text {AGR }
$$

Let us turn to the question of how the DIC structures are constructed. As assumed earlier, morphological construction operates cyclically from the bottom up, and creates the structure in (83), which is identical to that in (81) except that the lower AGR is assigned the feature [+pronominal] by (82). (Remember that DICs are possible only in the present tense where $\mathrm{T}^{0}$ has a null exponent in Italo-Romance and therefore undergoes pruning. We use the V1 passare to avoid the morphophonological complexities in the verbs andare 'go' and venire 'come' 26 ):

${ }^{26}$ Andare 'go' requires suppletion ( $v a$ in the present) (see, a.o., Pomino \& Remberger 2019). In addition, the independently required morpho-phonological rule of TV deletion before a vowel-initial suffix (TV $\rightarrow$ $\varnothing / \ldots$ V) must apply. A further rule deletes the thematic vowel in the 3 rd plural in venire and andare.
} 
(83)

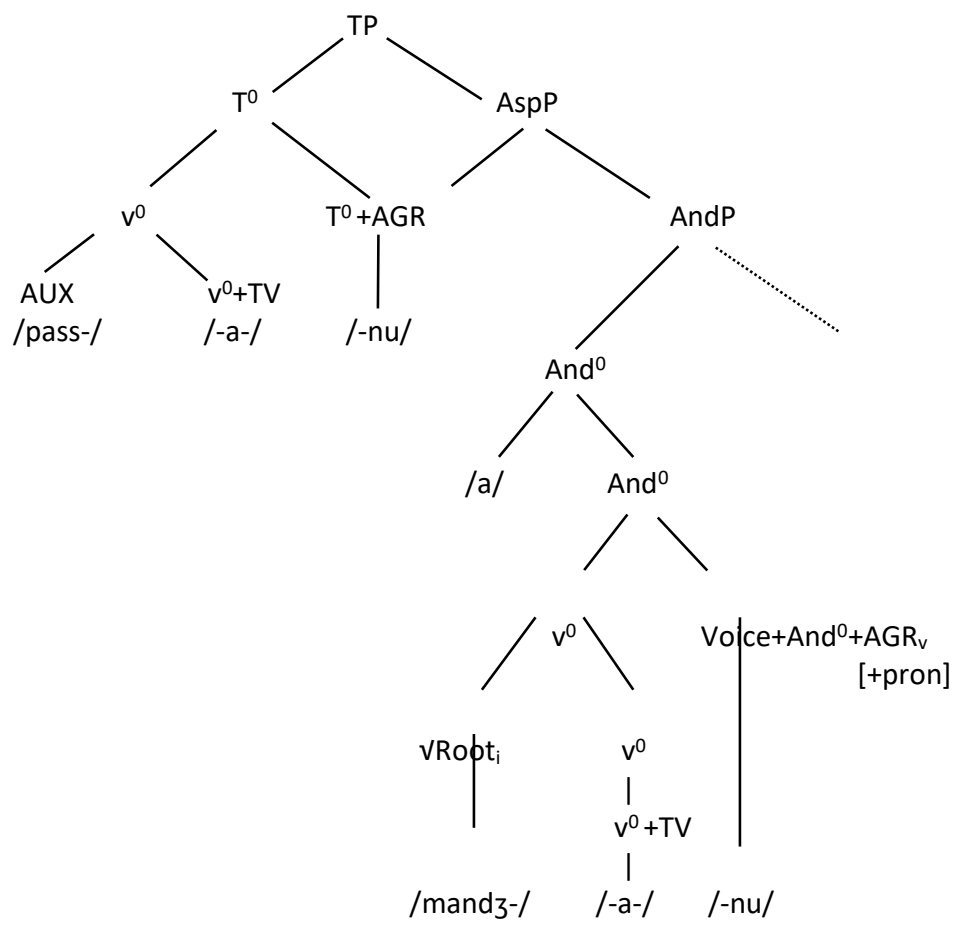

With regard to the defectiveness of the paradigm, we have seen that DICs are often not available in the 1st and 2nd plural. It is not the case, however, that in the dialects with defective paradigms it is impossible to say 'we are going to eat' or 'you (PL) are going to eat'. The issue is rather that the relevant DIC cannot be for that purpose, and instead a construction where $\mathrm{V} 2$ is uninflected, i.e. an infinitive, is used. The actual problem, then, is the use of DIC in the 1st and 2nd plural. We have already drawn a correlation between the defectiveness of DIC and Maiden's N-pattern. Following Calabrese (2019), the special behaviour of the 1st and 2 nd plural in the $\mathrm{N}$-pattern can be accounted for by assuming that the regular morphology that appears in these persons is the result of an impoverishment operation. For example, in the case of the present tense of the Italian verb uscire 'go out' (esco, esci, esce, usciamo, uscite, escono), which presents a case of root alternation, impoverishment deletes the root diacritic that triggers the special ablaut changing $u$ to $e$ in the present. The assumption is that diacritics are the means through which information about irregular morphological behaviour is represented in morphology; once a diacritic is deleted, regular morphology arises.

Calabrese (2019) in fact shows that impoverishment can be used to account for cases of regularization or morphological levelling in traditional grammars. For example, in the history of English we see cases of regularization of strong past forms as in (84): 
(84)

$$
\begin{aligned}
& \begin{array}{l}
\text { clomb } \\
\text { crope }
\end{array} \quad \Rightarrow \text { climbed } \\
& \text { lough } \Rightarrow \text { laughed } \\
& \text { yold } \Rightarrow \text { yielded } \\
& \text { holpen } \Rightarrow \text { helped }
\end{aligned}
$$

The regularization we observe in (84) can be achieved by impoverishing the special root index required for the application of special Vocabulary Items and MP Rules; in other words, the lexical information necessary for their application is made unavailable. Therefore, the regular forms appear. Formally, we can say that climb in (84) loses the lexical markings $Y$ and $Z$ that are required for the application of the rules in (86) and (87) (Halle \& Marantz 1993): ${ }^{27}$

(85) $\operatorname{root}^{\mathrm{x}} \rightarrow$ impoverishment $\rightarrow$ root

(86) $[+$ past $]<-->-\varnothing / \operatorname{root}^{Y}$ where Root $^{\mathrm{Z}}=$ sell, tell, climb

$$
\text { V--> }\left(\begin{array}{c}
\text { +back } \\
\text { +round }
\end{array}\right) /\left[\mathrm{C}_{1} \ldots \mathrm{C}_{2}\right] \operatorname{Root}^{\mathrm{Z}}[+ \text { past }] / \text { where } \operatorname{root}^{\mathrm{Y}}=\text { beat, drive, bind, } \ldots .
$$

This provides us with an account of the changes in (84) (see Calabrese (2019) for more discussion). Let us now consider the following Italian verbal forms where special morphological operations apply in all persons except 1st and 2nd (and in the forms that are always regular: the imperfect and the infinitive): morphophonological rules in (88a-e), insertion of extension /-isk-/ in (88f), suppletion in (88g) and irregular deletion of imperfect marker (88h)).

\footnotetext{
지구

${ }^{27}$ With this we want to capture the idea that the innovation involves forgetting/not accessing for some reason the information (the diacritic) needed for the application of the rule, which remains the same.
} 
(88)

$\begin{array}{lllllll} & \text { 1SG } & \text { 2SG } & \text { 3SG } & \text { 1PL } & \text { 2PL } & \text { 3PL } \\ \text { a. venni } & \text { venisti } & \text { venne } & \text { venimmo } & \text { veniste } & \text { vennero } & \text { 'come' (past) } \\ \text { b. misi } & \text { mettesti } & \text { mise } & \text { mettemmo } & \text { metteste } & \text { misero } & \text { 'put' (past) } \\ \text { c. feci } & \text { facesti } & \text { fece } & \text { facemmo } & \text { faceste } & \text { fecero } & \text { 'do' (past) } \\ \text { d. odo } & \text { odi } & \text { ode } & \text { udiamo } & \text { udite } & \text { odono } & \text { 'hear' } \\ \text { e. esco } & \text { esci } & \text { esce } & \text { usciamo } & \text { uscite } & \text { escono } & \text { 'go out' } \\ \text { f. finisco } & \text { finisci } & \text { finisce } & \text { finiamo } & \text { finite } & \text { finiscono } & \text { 'finish' } \\ \text { g. vado } & \text { vai } & \text { va } & \text { andiamo } & \text { andate } & \text { vanno } & \text { 'go' } \\ \text { h. ero } & \text { eri } & \text { era } & \text { eravamo } & \text { eravate } & \text { erano } & \text { 'be' (imperfect) }\end{array}$

As discussed in Calabrese $(2011,2012,2019)$, the appearance of regular morphology in 1st and 2 nd plural can be readily accounted for by assuming that the regularizations we observe in these persons involve repair operations implementing deletion-impoverishment - of featural diacritics. This impoverishment characterizes all Italo-Romance varieties (see Calabrese 2019 for discussion of its origins). For example, the cases in (88) can be accounted for by assuming that they involve impoverishment of the diacritic that triggers contextual allomorpy: morphophonological rules in (88a-f,h) and VIs (for suffixal (88a)) and root suppletion (88g)) (see also Calabrese 2012).

If we adopt this account of the special behaviour of the 1st and 2nd plural, we can then propose the following explanation for the defectiveness observed in DIC constructions. These constructions are characterized by special morphological behaviour-a [+pronominal] AGR in V2. We can therefore say that it is this feature that is impoverished in the context of the 1st and 2nd plural, which accounts for the defectiveness in those persons and for the emergence of the regular infinitival V2 in this case. This is illustrated in (89):

$$
[+ \text { pronominal }] \rightarrow \varnothing /[\ldots,+ \text { participant, }+ \text { plural }]_{\text {And }}{ }^{0}+\text { AGR }
$$

Once deleted, the feature [+pronominal] is replaced by its opposite [-pronominal] and AGR is morphologically realized as infinitival (on this specific issue, see also Lorusso 2019).

\section{The loss of agreement}

Let us now turn to the two final stages of grammaticalization of the MVC, where V1 is morphologically simplified by losing AGR and becomes an uninflected affix-like element. It is important to observe that there are cases in which the absence of an overt agreement marker is purely a surface property of the AGR exponent as in the following case: 
(90)

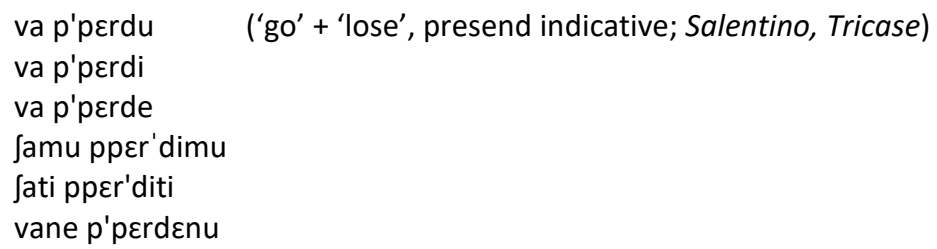

In this case the best analysis is one that assumes the presence of a higher AGR node for the andative auxiliary $\left(A G R^{1}\right)$ and the AGR VIs in (91): ${ }^{28}$
a. /-mu/ <--> $[\text { +part, +auth, +plur }]_{\mathrm{AGR}}{ }^{1}$
b. /-ti/ $<-->$ [+part, + plur $]_{A G R}{ }^{1}$
c. $/$-ti/ $<->\quad[- \text { part, }+ \text { plur }]_{A G R}{ }^{1}$
d. $/-\varnothing /<-->$ [-plur $]_{A G R}{ }^{1}$

Table 5 shows the paradigms for the dialects of Putignano (from Ledgeway 2016: 168) and Lecce. If we compare the Campi dialect with those of Putignano and Tricase (see (90)), it emerges that radical reduction inflectional AGR endings has operated in the dialect of Campi, although there is still preservation of exponential suppletion (see Calabrese $2020 b$ for an analysis) in the present, while some more specified inflectional forms are still used in the present forms in the dialects of Tricase and Putignano.

[?]

${ }^{28}$ Interestingly, a similar process of affixation with a MVC has been reported for central American varieties of Spanish (Anderson 1979, Fleischman 1982: 116, Schwegler 1990: 146), as shown in the following table:

\begin{tabular}{|lll|}
\hline & STANDARD SPANISH & SELECTED AMERICAN DIALECTS \\
\hline 1SG & voy a dormir & yo v(w)adormir \\
2SG & vas a dormir & tu va:dormir \\
3SG & va a dormir & el va:dormir \\
1PL & vamos a dormir & nosotros vamos a dormir \\
2PL & van a dormir & Uds. va ${ }^{n}$ a dormir \\
3PL & van a dormir & ellos va ${ }^{n}$ a dormir \\
\hline
\end{tabular}

In Fleischman's (1982: 116) and Schwegler's (1990: 146) description of these data, it is argued that Panamanian speakers have taken 2nd and 3rd person singular as point of departure, assimilating the linking $a$ between the two verbs and producing a lengthened vowel. From here the morphologized form seems to (optionally) extend to 1st person singular and, since the final $-n$ in van is only weakly articulated, it might eventually regularize to the corresponding cells of the paradigm too. Fleischman (1982: 116) additionally provides a list of projected forms, that is the extension of the innovative synthetic form vadormir to all persons, including the plural persons. It would be very interesting to verify whether the predicted regularization has since taken place, a task that we leave for future research. 
Table 5: DIC in the dialects of Putignano (Bari) and Campi (Lecce)

\begin{tabular}{|c|c|c|}
\hline & Putignano (BA) & Campi (LE) \\
\hline & $' g o+d o^{\prime}$ & 'go + lose' \\
\hline \multirow[t]{6}{*}{ present } & vok a f'fattsu & bba p'perdu \\
\hline & vع f'fa]ə & bba p'perdi \\
\hline & vع f'faJə & bba p'perde \\
\hline & Ja fa'Jeimə & $\iint a$ pper'dimu \\
\hline & Ja fa'Jeitə & $\iint a$ pper'diti \\
\hline & von a f'faJənə & bba p'perdenu \\
\hline \multirow[t]{6}{*}{ past } & $\int \varepsilon$ ffa'Jevəə & Ja pper'dia \\
\hline & $\int \varepsilon \mathrm{ffa}$ 'Jivəə & $\int a$ pper'dia \\
\hline & $\int \varepsilon$ ffa'Jevəə & $\int a$ pper'dia \\
\hline & $\int \varepsilon$ ffa'femməə & Ja pper'diamu \\
\hline & $\int \varepsilon \mathrm{ffa} /$ 'jivəəvəə & $\int a$ pper'diuvu \\
\hline & $\int \varepsilon \mathrm{ffa} / \mathrm{e}$ evəənəə & Ja pper'dianu \\
\hline
\end{tabular}

As mentioned in Section 2, a type of radical impoverishment similar to that observed in the dialect of Campi is found in western and central Sicily, but in this case a defective paradigm is the target of the morphological simplification (Cardinaletti \& Giusti 2001, 2003, 2019, Cruschina 2013):

\begin{tabular}{|c|c|c|c|}
\hline (92) & $1 \mathrm{SG}$ & vaju a pigghiu & va a pigghiu \\
\hline & $2 \mathrm{SG}$ & vai a pigghi & va a pigghi \\
\hline & $3 \mathrm{SG}$ & va a pigghia & va a pigghia \\
\hline & $3 P L$ & vannu a pigghianu / & va a pigghianu \\
\hline & MPER. 2SG & va pigghia & va pigghia \\
\hline
\end{tabular}

Recall that in these Sicilian dialects, the impoverished forms are not limited to the verb $\mathrm{GO}$, but are also found with other motion verbs, and that the DIC version with invariant $v a$ as $\mathrm{V} 1$ coexists with the version in which Go displays regular endings.

In some areas of eastern Sicily (e.g. Marina di Ragusa, Acireale) the grammaticalization of V1 appears to have reached the final stage of affix, as discussed in Section 2. The relevant data are repeated below for convenience:
a. Voppigghju u pani. go+fetch.1sG the bread
1SG
b. Voppigghi u pani.
2SG
c. Vopigghja u pani.
3SG
d. Voppigghjamu u pani.
$1 \mathrm{PL}$
e. Voppigghjati u pani.
2PL

(Marina di Ragusa, Sicily)

[full paradigm] ... 
c. Voppigghjanu u pani.

(94)

a. Occattu u giunnali. go+buy.1SG the newspaper 1SG

b. Occatti u giunnali. 2sG

c. Occattunu u giunnali. 3PL ... [full paradigm] ...
3PL

(Acireale, Sicily)

When AGR morphology is systematically absent, one can assume a systematically phonologically empty AGR, that is, extending (91d) to all persons. We assume, however, that the most adequate analysis is that in which the andative morpheme is simply analysed as a prefix and is thus represented as in (95) (after head movement and AGR insertion):

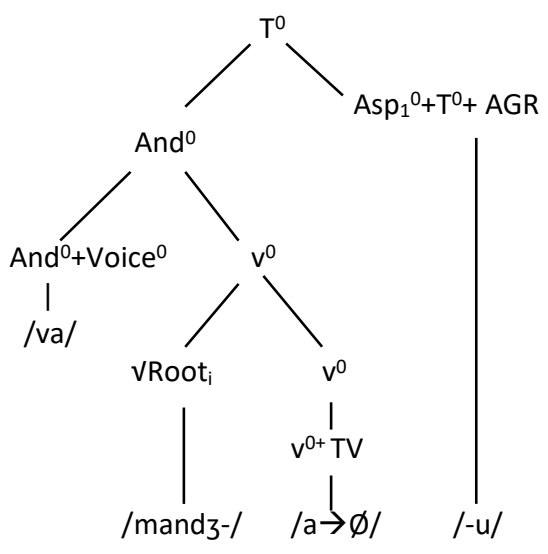

Crucially, the $\mathrm{And}^{0}$ exponent in this case must be marked as being antitropal, that is, as a prefix). ${ }^{29}$ The structure in (95) is generated by simply allowing head movement to apply

적?

${ }^{29}$ The prefixal nature of the andative element is confirmed not only by the fact that it can never be separated from the verbal complex, for example by a clitic pronoun (i) or by an adverb (ii), but also by the peculiar position of the andative element in present perfect forms (see (iii)):

(i) a. *bba lu kkattu

go it= buy.PRS.1SG

b. Iu bba kattu

it= go buy.PRS.1sG

'I go to buy it'

(ii) a. *bba sempreffatiu, la matina.

go always WORK.PRS.1sG the morning

b. bba ffatiu sempre, la matina.

go WORK.PRS.1SG always the morning

'I always go towork in the morning' 
to the entire extended projection of $\mathrm{v}^{0}$, without blocking. No auxiliary headed by And ${ }^{0}$ would then be created and no AGR would be inserted in the case of V1. Given that free head movement to the highest projection as in (95) is independently required to generate this structure, there is simply no need to assume the presence of phonologically empty AGR in V1: indeed, this account offers a solution that is theoretically more parsimonious.

\section{Conclusions}

In this paper we have attempted to capture the syntactic and morphological properties and processes that determine the different shades of microvariation in southern Italian MVCs. Concentrating on the cases of restructuring where V1 is a functional verb, we integrated Cinque's (1999) model of functional projections into Distributed Morphology so as to arrive at a syntactic model of word construction. Within this approach, no operation of fusion need be stipulated, but the morphosyntactic features of functional heads are moved upwards cyclically generating complex heads and being available for further vocabulary insertion. Nodes with non-overt exponents are pruned.

Following in particular Calabrese (2019), we accounted for the characteristic properties of several MVCs: the difference between Infinitival MVC and the MVC with double inflection (DIC), the defective paradigm of certain MVCs, and the morphological reduction of the motion $\mathrm{V} 1$, which has reached affix status in some constructions. While the infinitive is the morphological realization of a [-pronominal] agreement node lacking phi-features, DIC arises from an identical structure in which AGR is assigned the feature [+pronominal], thus agreeing with V1 in person and number. The special behaviour of the 1st and 2nd plural in the defective paradigms is then accounted for as the result of an operation of impoverishment that applies with these persons. When V1 displays no agreement morphology, we propose that the andative morpheme is simply analysed as a prefix: no independent auxiliary is created and no AGR is inserted.

In southern Italian dialects, all these properties and processes interact and co-exist in different ways, giving rise to a great deal of microvariation. With this study, we thus

??

(iii) l'addzu $\iint a$ kkattatu

it=have.PRS.1sg go-buy.PTCP

'I went to buy it'

In (iii) the andative element appears as a prefix on the past participle below the auxiliary. This periphrastic structure is easily derivable if head movement of the andative head is allowed but not that of the [+Perfect] aspectual head (see Calabrese 2020b for detailed discussion). 
hope to have contributed to the analysis of microvariation patterns through the tools and insights of formal and theoretical linguistics.

Acknowledgments: We are grateful to Eva-Maria Remberger for her costant support and valuable feedback, and to two anonymous reviewers for their comments and suggestions. We would also like to thank Guglielmo Cinque for helpful discussion and fruitful remarks.

\section{References}

Anderson, Eric W. 1979. The development of the Romance future tense: morphologization and a tendency toward analyticity. Papers in Romance 1. 21-35.

Andriani, Luigi. 2017. The syntax of the dialect of Bari. Cambridge: University of Cambridge dissertation.

Arregi, Karlos \& Asia Pietraszko. 2018. Generalized Head Movement. In Patrick Farrell (ed.), Proceedings of the LSA, Volume 3, 5. 1-15. Washington, DC: Linguistic Society of America.

Ascoli, Graziadio I. 1896. Un problema di sintassi comparata dialettale. Archivio glottologico italiano 14. 453-468.

Ascoli, Graziadio I. 1901. Appendice all'articolo Un problema di sintassi comparata dialettale. Archivio glottologico italiano 15. 221-225.

Baker, Mark. 2010. The syntax of agreement and concord. Cambridge: Cambridge University Press.

Béjar, Susana \& Milan Rezac 2009. Cyclic agree. Linguistic Inquiry 40. 35-73.

Bjorkman, Bronwyn Alma Moore. 2011. BE-ing default: The morphosyntax of auxiliaries. MIT dissertation.

Bobaljik, Jonathan. 2000. The ins and outs of contextual allomorphy. In Kleanthes Grohmann \& Caro Struijke (eds.), Proceedings of the Maryland Mayfest on Morphology 1999, 35-71. College Park: University of Maryland, Department of Linguistics.

Bon, Noëllie. 2014. Une Grammaire de la Langue Stieng: Langue en Danger du Cambodge et du Vietnam [A Grammar of the Stieng Language: An Endangered Language in Cambodia and Vietnam]. Lyon: University Lumiere Lyon 2 dissertation.

Bošković, Željko. 2014. Now I'm a phase, now I'm not a phase: On the variability of phases with extraction and ellipsis. Linguistic Inquiry 45. 27-89.

Bybee, Joan, Revere Perkins \& William Pagliuca. 1994. The evolution of grammar: Tense, aspect and modality in the languages of the world. Chicago: University of Chicago Press.

Calabrese, Andrea. 2008. On absolute and contextual syncretism. Remarks on the structure of paradigms and on how to derive it. In Andrew Nevins \& Asef Bachrach (eds.), The bases of Inflectional Identity, 156-205. Oxford: Oxford University Press. 
Calabrese, Andrea. 2011. Investigations on markedeness, syncretism and zero exponence in morphology. Morphology 21(2). 283-325.

Calabrese, Andrea. 2012. Allomorphy in the Italian passato remoto: A Distributed Morphology analysis. Language and Information Society 1-75. Sogang University, Korea.

Calabrese, Andrea. 2019. Morphophonological Investigations: A Theory of PF. From syntax to phonology in Italian and Sanskrit verb forms. Ms., University of Connecticut.

Calabrese, Andrea. 2020a. Remarks on the role of the perfect participle in Italian morphology and on its history. To appear in lan Roberts \& Adam Ledgeway (eds.), Probus, special issue on Romance Historical Linguistics.

Calabrese, Andrea. 2020b. The morphosyntax of andative forms in the Campiota vernacular. The synthetic behavior of restructuring roots. Ms, University of Connecticut.

Cardinaletti, Anna \& Giuliana Giusti. 2001. Semi-lexical motion verbs in Romance and Germanic. In Norbert Corver \& Henk van Riemsdijk (eds.), Semi-lexical categories. On the function of content words and the content of function words, 371-414. Berlin: Mouton de Gruyter.

Cardinaletti, Anna \& Giuliana Giusti. 2003. Motion verbs as functional heads. In Cristina Tortora (ed.), The syntax of Italian dialects, 31-49. Oxford \& New York: Oxford University Press.

Cardinaletti, Anna \& Giuliana Giusti. 2019. Multiple agreement in southern Italian dialects. In Ludovico Franco \& Paolo Lorusso (eds.), Linguistic Variations: Structure and Interpretation. Studies in Honor of M. Rita Manzini, 125-147. Berlin: Mouton De Gruyter.

Cardinaletti, Anna \& Ur Shlonsky. 2004. Clitic positions and restructuring in Italian. Linguistic Inquiry 35. 519-557.

Chia, Emmanuel N. 1976. Kom Tenses and Aspects. Washington, DC: Georgetown University dissertation.

Chomsky, Noam. 2000. Minimalist inquiries: The framework. In Roger Martin, David Michaels \& Juan Uriagereka (eds), Step by Step: Essays on Minimalist Syntax in Honor of Howard Lasnik, 89-155. Cambridge, MA: MIT Press.

Chomsky, Noam. 2001.Derivation by phase. In Michael Kenstowicz (ed.), Ken Hale: A Life in Language, 1-52. Cambridge, MA: MIT Press.

Christopoulos, Christos. 2018. Re-stricting the locality of contextual allomorphy. Ms., University of Connecticut.

Christopoulos, Christos \& Roberto Petrosino. 2017. Greek root allomorphy without spans. In Wm. G. Bennett, Lindsay Hracs \& Dennis Ryan Storoshenko (eds.), Proceedings of the 35th West Coast Conference in Formal Linguistics, 151-160. Somerville, MA: Cascadilla Proceedings Project.

Cinque, Guglielmo. 1999. Adverbs and functional heads. Oxford \& New York: Oxford University Press.

Cinque, Guglielmo. 2001. "Restructuring" and functional structure. In Laura Brugè (ed.), University of Venice Working Papers in Linguistics 11. 45-127.

Cinque, Guglielmo. 2006. Restructuring and functional heads. Oxford \& New York: Oxford University Press.

Cinque, Gugliemo. 2017. On the status of functional categories (heads and phrases). Language and Linguistics 18(4). 521-576. 
Cruschina, Silvio. 2013. Beyond the stem and inflectional morphology: An irregular pattern at the level of periphrasis. In Silvio Cruschina, Martin Maiden \& J. C. Smith (eds.), The boundaries of pure morphology. Diachronic and synchronic perspectives, 262-283. Oxford: Oxford University Press.

Cruschina, Silvio. 2018. The 'go for' construction in Sicilian. In D'Alessandro, Roberta \& Diego Pescarini (eds.), Advances in Italian dialectology: Sketches of Italo-Romance grammars, 292-320. Leiden: Brill.

Cruschina, Silvio. in press. Gone unexpectedly: Pseudo-coordination and the expression of surprise in Sicilian. In Vincenzo Nicolò Di Caro, Giuliana Giusti \& Daniel Ross (eds.), Pseudo-Coordination and Multiple Agreement Constructions. Amsterdam: John Benjamins.

Del Prete, Fabio \& Giuseppina Todaro. 2020. Building complex events. The case of Sicilian Doubly Inflected Construction. Natural Language \& Linguistic Theory 38. 1-41.

Di Caro, Vincenzo Nicolò. 2015. Syntactic constructions with motion verbs in some Sicilian dialects: a comparative analysis. Venice: Ca' Foscari University MA thesis

Di Caro, Vincenzo Nicolò. 2018. The Inflected Construction in the dialects of Sicily. Parameters of microvariation. In Silvio Cruschina, Adam Ledgeway \& Eva-Maria Remberger (eds.), Italian dialectology at the interfaces, 63-78. Amsterdam: John Benjamins.

Di Caro, Vincenzo Nicolò. 2019. Multiple agreement constructions in southern in Italo-Romance. The syntax of Sicilian Pseudo-Coordination. Venice: Ca' Foscari University of Venice dissertation.

Embick, David. 2010. Localism versus Globalism in Morphology and Phonology. Cambridge, MA: MIT Press.

Embick, David \& Rolf Noyer. 2007. Distributed morphologyand the syntax-morphology interface. In Gillian Ramchand \& Charles Reiss (eds.), Oxford Handbook of Linguistic Interfaces, 289-324. Oxford: Oxford University Press

Fenger, Paula. 2018. Head movement: The view from failure Affixation, periphrasis and clitics. Ms., University of Connecticut.

Fenger, Paula. 2020. Words within Words: The Internal Syntax of Words. Storrs, Connecticut: University of Connecticut dissertation.

Fleischman, Suzanne. 1982. The future in thought and language. diachronic evidence from Romance. Cambridge: Cambridge University Press.

Halle, Morris \& Alec Marantz. 1993. Distributed Morphology and the pieces of inflection. In Kenneth Hale \& Samuel Jay Keyser (eds.), The View from Building 20: Essays in linguistics in honor of Sylvain Bromberger, 111-176. Cambridge, MA: MIT Press.

Harizanov, Boris \& Vera Gribanova. 2019. Whither head movement? Natural Language \& Linguistic Theory 37. 461-522.

Harrison, Sheldon P. 1976. Mokilese Reference Grammar. Honolulu: University of Hawai'i Press.

Holton, Gary. 2014. Western Pantar. In Antoinette Schapper (ed.), The Papuan Languages of Timor, Alor and Pantar Vol. 1: Sketch Grammars, 23-96. Berlin: De Gruyter Mouton.

Kiparsky, Paul. 2004. Blocking and periphrasis in inflectional paradigms. Yearbook of Morphology 2004. 113-135. 
Ledgeway, Adam. 2016. From coordination to subordination: The grammaticalisation of progressive and andative aspect in the dialects of Salento. In Fernanda Pratas, Sandra Pereira \& Clara Pinto (eds.), Coordination and Subordination. Form and Meaning - Selected Papers from CSI Lisbon 2014, 157-184. Cambridge: Cambridge Publishing Scholars.

Leone, Alfonso. 1973. Vattel'a pesca, vieni a piglialo. Lingua Nostra 34. 11-13.

Lorusso, Paolo. 2019. A person split analysis of the progressive forms in some Southern Italian varieties. In Silvio Cruschina, Adam Ledgeway \& Eva-Maria Remberger (eds.), Italian dialectology at the interfaces, 203-236. Amsterdam: John Benjamins.

MacDonald, Lorna. 1985. A Grammar of Tauya. Winnipeg: University of Manitoba dissertation.

Maiden, Martin. 2004. Verb augments and meaninglessness in early Romance morphology. Studi di grammatica italiana 22.1-61.

Maiden, Martin. 2005. Morphological autonomy and diachrony. Yearbook of Morphology 2004. 137-175.

Maiden, Martin. 2018. The Romance Verb: Morphomic Structure and Diachrony. Oxford: Oxford University Press.

Manzini, M. Rita \& Leonardo M. Savoia. 2005. I dialetti italiani e romanci. Morfosintassi generativa. Alessandria: Edizioni dell'Orso.

Oltra-Massuet, Isabel \& Karlos Arregi. 2005. Stress-by-structure in Spanish. Linguistic Inquiry 36. 43-84.

Pietraszko, Asia. 2016. The syntax of simple and compound tenses in Ndebele. Proceedings of the Linguistics Society of America Annual Meeting 1(18). 1-15.

Pietraszko, Asia. 2018. Auxiliary vs INFL in Bantu. The syntactic and phonological complexity of Ndebele verbs. Natural Language and Linguistic Theory 36(1). 265-308.

Pomini, Natascha \& Eva-Maria Remberger. 2019. Verbal suppletion in Romance diachrony: The perspective of Distributed Morphology. In Frans Plank \& Nigel Vincent (eds.), LifeCycle of Suppletion. Special Issue of the Transactions of the Philological Society 117(3). 471-497.

Prins, Maria Clazina. 2011. A Web of Relations: A Grammar of rGyalrong Jiăomùzú (Kyomkyo) Dialects. Leiden: Leiden University dissertation.

Pustet, Regina, Juliana Wijaya \& Than Than Win. 2006. Progressives in typological perspective. Languages in Contrast 6.2. 177-227.

Rizzi, Luigi. 1976. Ristrutturazione. Rivista di grammatica generativa 1. 1-54.

Rizzi, Luigi. 1978. A Restructuring Rule in Italian Syntax. In Samuel Jay Keyser (ed.), Recent transformational studies in European languages, 113-158. Cambridge, MA: MIT Press.

Rizzi, Luigi. 1990. Relativized Minimality. Cambridge, MA: MIT Press.

Rohlfs, Gerhard. 1969. Grammatica storica della lingua italiana e dei suoi dialetti. Vol. 3: Sintassi e formazione delle parole. Turin: Einaudi.

Schwegler, Armin. 1990. Analyticity and Syntheticity: a diachronic perspective with special reference to Romance Languages. Berlin \& New York: Mouton de Gruyter.

Sornicola, Rosanna. 1976. Vado a dire o vaiu a ddico: problema sintattico o problema semantico?. Lingua Nostra 37. 65-74.

Squartini, Mario. 1998. Verbal periphrases in Romance. Berlin: Mouton de Gruyter. 
Todaro, Giuseppina \& Fabio Del Prete. 2018. The morphosyntax-semantics interface and the Sicilian Doubly Inflected Construction. In Silvio Cruschina, Adam Ledgeway \& Eva-Maria Remberger (eds.), Italian dialectology at the interfaces, 131-154. Amsterdam: John Benjamins.

Wurmbrand, Susanne. 2001. Infinitives: Restructuring and clause structure. Berlin: Mouton de Gruyter.

Wurmbrand, Susanne. 2004. Two types of restructuring: Lexical vs. functional. Lingua 114. 991-1014.

Wurmbrand, Susi. 2014. Tense and aspect in English infinitives. Linguistic Inquiry 45(3). 403447.

Wurmbrand, Susi. 2017. Verb clusters, verb raising, and restructuring. In Martin Everaert \& Henk van Riemsdijk (eds.), The Blackwell Companion to Syntax 2, Second Edition. Oxford: Blackwell. 